\title{
The Role of Glycerol and Its Derivatives in the Biochemistry of Living Organisms, and Their Prebiotic Origin and Significance in the Evolution of Life
}

\author{
Maheen Gull * and Matthew A. Pasek (D) \\ School of Geosciences, University of South Florida, 4202 E Fowler Ave., NES 204, Tampa, FL 33620, USA; \\ mpasek@usf.edu \\ * Correspondence: maheengull@usf.edu; Tel.: +1-813-974-8979
}

check for

updates

Citation: Gull, M.; Pasek, M.A. The Role of Glycerol and Its Derivatives in the Biochemistry of Living Organisms, and Their Prebiotic Origin and Significance in the Evolution of Life. Catalysts 2021, 11, 86. https://doi.org/10.3390/ catal11010086

Received: 10 December 2020 Accepted: 7 January 2021 Published: 10 January 2021

Publisher's Note: MDPI stays neutral with regard to jurisdictional clai$\mathrm{ms}$ in published maps and institutional affiliations.

Copyright: (C) 2021 by the authors. Licensee MDPI, Basel, Switzerland. This article is an open access article distributed under the terms and conditions of the Creative Commons Attribution (CC BY) license (https:// creativecommons.org/licenses/by/ $4.0 /)$.

\begin{abstract}
The emergence and evolution of prebiotic biomolecules on the early Earth remain a question that is considered crucial to understanding the chemistry of the origin of life. Amongst prebiotic molecules, glycerol is significant due to its ubiquity in biochemistry. In this review, we discuss the significance of glycerol and its various derivatives in biochemistry, their plausible roles in the origin and evolution of early cell membranes, and significance in the biochemistry of extremophiles, followed by their prebiotic origin on the early Earth and associated catalytic processes that led to the origin of these compounds. We also discuss various scenarios for the prebiotic syntheses of glycerol and its derivates and evaluate these to determine their relevance to early Earth biochemistry and geochemistry, and recapitulate the utilization of various minerals (including clays), condensation agents, and solvents that could have led to the successful prebiotic genesis of these biomolecules. Furthermore, important prebiotic events such as meteoritic delivery and prebiotic synthesis reactions under astrophysical conditions are also discussed. Finally, we have also highlighted some novel features of glycerol, including glycerol nucleic acid (GNA), in the origin and evolution of the life.
\end{abstract}

Keywords: glycerol; phosphorylation; catalysis; prebiotic syntheses; origin of life; evolution of cell membranes; deep eutectic solvents; extremophiles; glycerol biochemistry; phospholipids; early Earth

\section{Introduction}

Glycerol $\left(\mathrm{C}_{3} \mathrm{H}_{8} \mathrm{O}_{3}\right)$, also known as propane-1,2,3-triol, is a significant biomolecule [1]. It is chemically classified as a 'polyol with a molar mass of $92.09382 \mathrm{~g} / \mathrm{mol}$, a density of $1.26 \mathrm{~g} / \mathrm{cm}^{3}$, and a boiling point of $554^{\circ} \mathrm{F}\left(290^{\circ} \mathrm{C}\right)$.

Glycerol is produced by human physiology and is a product of other living organisms. It is the structural backbone of lipid molecules (triacylglycerols) and is considered to be an important metabolite in living organisms [1]. It is synthesized from sn-glycerol-3phosphate in the presence of an enzyme called glycerol-3-phosphate phosphatase [2]. snglycerol-3-phosphate is formed from 1,3-dihydroxyacetone phosphate (DHAP, hereafter), a glycolytic product, catalyzed by the enzyme glycerol phosphate dehydrogenase or from dihydroxyacetone (DHA, hereafter), catalyzed by glycerol dehydrogenase [1,3,4]. Such biochemical reactions are in equilibrium and hence are reversible depending on the substrate and product levels in the reactions. The enzymes that catalyze the reactions of glycerol are tissue-specific: e.g., glycerol kinase and glycerol dehydrogenase are chiefly found in the liver and kidney $[1,3,4]$. Small amounts of enzymes such as glycerol kinase and glycerol dehydrogenase have been found in skeletal muscle [5] as well as intestinal mucosa [6,7] while glycerol phosphate dehydrogenase is mainly found in skeletal muscle, the liver, and adipose tissue [6,7].

Another biochemical process for the formation of glycerol is the de-esterification reaction (or also known as lipolysis) of triacylglycerols [8] that mainly takes places in adipose tissue, skeletal muscle, the liver, and in blood circulating through blood vessels 
that are lined with lipoprotein lipase [8]. The most significant form of glycerol is sn-glycerol3-phosphate, which directly takes part in the biochemical synthesis of lipids [1].

The key metabolic pathway of lipogenesis (formation of triacylglycerols) occurs in adipose tissue, liver, muscle, heart, and the pancreas, and requires glycerol and its derivatives such as glycerol phosphates and fatty acid esters of glycerol (acylglycerols). Such metabolic pathways maintain and control energy homeostasis in the living organisms [9]. It has been found that white adipose tissues (WAT) secrete copious amounts of glycerol [10,11]. As mentioned earlier, glycerol is also produced as a by-product of lipolysis of triacylglycerols $[8,10,12]$. While WAT's capacity to regenerate glycerol is extremely limited [10,13], glycerol is the key substrate for hepatic gluconeogenesis as well as for many other biochemical reactions taking place in living organisms $[10,14]$. In addition to it taking part in hepatic gluconeogenesis, glycerol is also catalyzed by the enzyme glycerol kinase to form sn-glycerol-3-phosphate that then takes part in the biosynthesis of acylglycerols [10].

Glycerol is also the main low molecular weight compound in birds' eggs, completely replacing glucose during the first stages of embryonic development $[10,15]$. Furthermore, in many species of plants and yeasts, formation of glycerol from sn-glycerol-3-phosphate favors its accumulation in living cells as a response to metabolic stress caused by harsh environmental conditions [10,16]. In WAT, glycerol becomes the waste product of lipolysis and thus gets converted into glucose, thus providing a significant source of glucose for hibernating animals such as the black bear [17]. The North American fish species rainbow smelt (Osmerus mordax) is known to depress the freezing point of body fluids by using a mixture of antifreeze protein and glycerol [18-20].

In some fungi and algae, the intracellular glycerol concentration can reach as high as $7-8 \mathrm{M}$, which might act as a stress factor in certain yeasts (or fungi) [21,22]. The significance of glycerol, its metabolism, and its transportation in yeasts (e.g., Saccharomyces cerevisiae) has been extensively discussed [21,23]. In Saccharomyces cerevisiae and many other yeasts, glycerol is synthesized in the cytosol of the cell by the reduction of DHAP to sn-glycerol-3phosphate which undergoes dephosphorylation to form glycerol [24-26]. Glycerol is also an important nutrient for the cell-wall-less bacteria of the genus Mycoplasma [27]. This particular genus belongs to pathogens that derive glycerol from the lipids of their hosts (humans or animals) [27]. The role of glycerol in extremophiles is discussed in detail in Section 3.

As discussed above, glycerol serves as the backbone of lipid molecules. It plays a central role in the formation of acylglycerols (simple lipids) and phospholipids (complex lipids). Both simple lipids and complex lipids play a central role in the formation of cell membranes in the living organisms and phosphorylated derivatives of glycerol. For example, glycerol phosphates play a significant role in the formation of cell membranes in living beings [1]. Glycerol phosphates (e.g., sn-glycerol-3-phosphate or sn-glycerol-1phosphate and glycerol-2-phosphate) together with proteins make up the membranes of cells. Glycerol phosphate (with phosphate at the terminal carbon of glycerol) constitutes an essential part of the phospholipids.

Glycerol also plays a crucial role in the various metabolic pathways such as cellular respiration and photosynthesis. In vivo, glycerol is converted into products such as DHA, glyceraldehyde, and glyceric acid. These oxidized products of glycerol sustain metabolic pathways. For example, in glycolysis, glycerol is oxidized to DHA, the simplest ketone sugar, and this molecule actively takes part in respiration in higher plants and animals [28]. Its phosphorylated derivative, DHAP, is also an important intermediate in metabolic pathways such as glycolysis and the Calvin cycle, which is part of photosynthesis.

Another oxidation product of glycerol is glyceraldehyde, which is an intermediate in the metabolism of fructose sugar. Its phosphorylated derivative glyceraldehyde-3phosphate is considered to be a high-energy intermediate that facilitates the generation of ATP (adenosine triphosphate) [29]. Similarly, glyceric acid and its phosphorylated derivatives such as 2-phosphoglyceric acid, 3-phosphoglyceric acid, 2,3-diphosphoglyceric acid, and 1,3-diphosphoglyceric acid all play central roles in glycolysis [30]. The bacterial 
species Gluconobacter oxydans is capable of converting glycerol into glyceric acid, implying a facilitated conversion of glycerol into glyceric acid [31].

The review attempts to address the question of a potential prebiotic origin of glycerol and its associated chemical derivatives on the early Earth and discusses how these compounds would have taken part in the development of early life and 'cell-like compartments'. Moreover, in addition to taking part in cellular metabolism and formation of cell membranes, this review attempts to show how these compounds play significant roles in sustaining life that exists today. Furthermore, we shall also discuss the derivatives of glycerol used in modern biochemistry, which then justifies the types of compounds needed in a potential prebiotic chemistry. In doing so, some of the reactions that may lead to key molecules and to environments where these reactions may occur might be elucidated. An overview of the compounds to be discussed later are briefly listed in Figure 1.

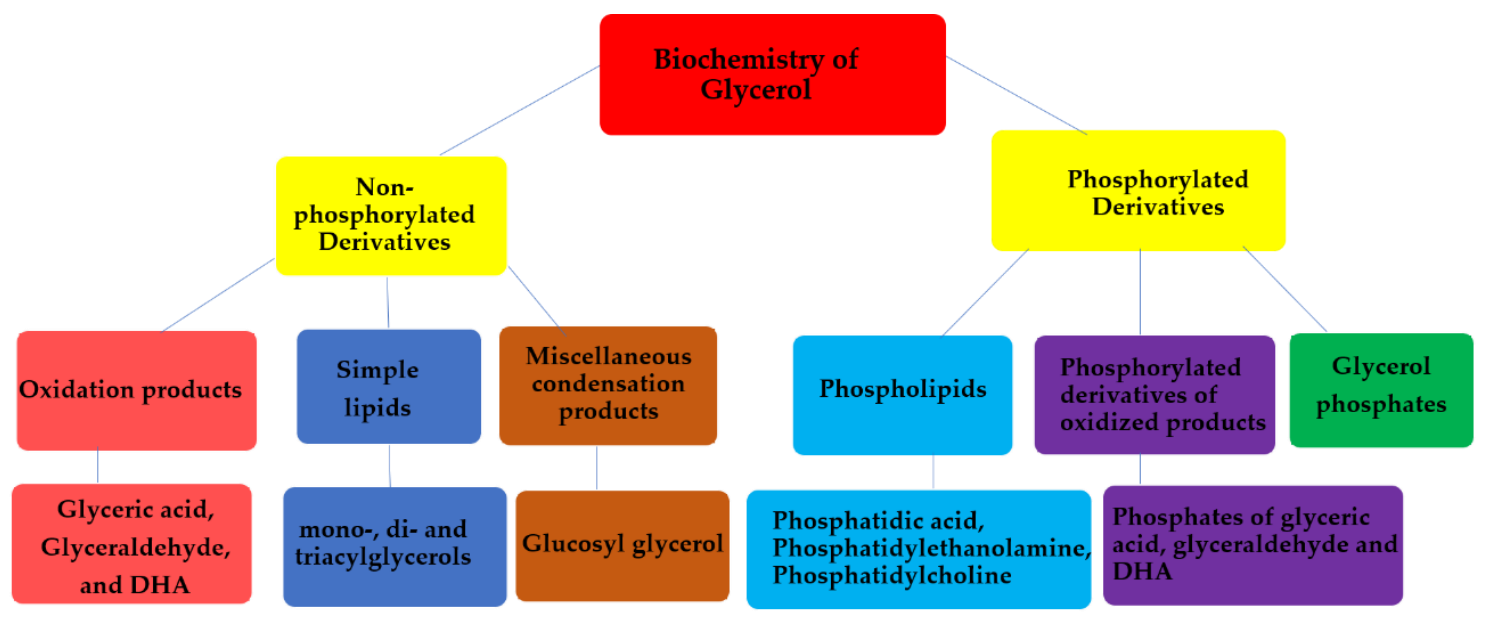

Figure 1. Flowsheet diagram of the important derivatives of glycerol that play important roles in biochemistry.

\section{The Varieties of Glycerol Used by Modern Biochemistry}

In order to understand the origin and evolution of early membranes, it is important to understand the role of glycerol phosphates in phospholipids. Phospholipids are amphiphilic macromolecules that contain fatty acids linked to glycerol phosphate. Glycerol phosphates constitute the polar part of the phospholipids and may also link through a phosphate diester to form a structure called a 'head group'. Important examples of phospholipids include phosphatidic acids, phosphatidylethanolamines, phosphatidylcholines, and phospohatidylserine.

Glycerol phosphate is an achiral molecule, whereas phospholipids have a stereogenic center at the second carbon of glycerol and on the basis of this stereogenic center, different types of glycerol phosphates are used in archaea compared to eukaryotes and bacteria. The naturally occurring enantiomer of the diacylglycerol phospholipids found in eukaryotes and bacteria is always D (also known as sn-glycerol-3-phosphate) [32,33], whereas the naturally occurring enantiomer of the phospholipidic isoprenoid glycerol ethers in archaeal cell membranes is L (also referred as sn-glycerol-1-phosphate) [34]. Bacteria and eukaryotes share similar membrane biochemistry, with ester-linked fatty acid-based phospholipids that comprise of sn-glycerol-3-phosphate. These sn-glycerol-3-phosphate based phospholipids were considered to be universal, but studying the archaeal biochemistry revealed that archaeal phospholipids are formed of sn-glycerol-1-phosphate that is connected to isoprenoid chains via ether linkage [34]. It is perhaps due to this chemical difference that there are different phospholipid biosynthesis pathways.

The plausible studies of the origin of phospholipids and glycerol phosphates would help in understanding the evolution of membranes and their various structural aspects. Perhaps one of the intriguing questions is indeed the structural disparity in the cell membranes of eukaryotes and bacteria versus archaea. However, it is important to mention here 
that certain prebiotic synthesis reactions reported to have started from achiral glycerol and fatty acids or aldehydes and achiral condensing agents and yielded the racemic mixtures of the phospholipids [32-34], and have generally not focused on chirality.

Cell membranes in bacteria, archaea, and eukaryotes are composed of phospholipids as bilayers; however, in some thermophilic prokaryotes they are present as monolayers. Various proteins are embedded in these lipid layers [35]. Despite the similarity in the basic composition of phospholipids in archaea and eukaryotes as well as bacteria, there is remarkable difference with respect to chemical compositions and structures. As mentioned above, in eukaryotes and bacteria, sn-glycerol-3-phosphate is chemically linked via an ester linkage to fatty acids.

In archaea, there are three distinctive features of phospholipids that differ from other organisms [35-37]:

(1) Their phospholipids are comprised of sn-glycerol-1-phosphate

(2) The hydrophobic side chain is built of isoprenoid units

(3) The isoprenoid units are linked with glycerol-1-phosphate by an ether linkage [35-37] (Figure 2).<smiles>CCCCCCOC(COC(=O)COC(=O)CCCCCCCCC(C)(C)CC(C)(C)CC(C)(C)CCCCC)COP(=O)(O)O</smiles><smiles>CCC(C)CCC(C)(C)CCC(C)CCCCCCC(C)CCC(C)(C(C)C)C(C)C(C)(C)CCC(C)CC</smiles>

Figure 2. The basic phospholipid structural differences of the archaea versus eukaryotes and bacteria: (A) generic structure of phospholipids in most eukaryotes and bacteria that contain unbranched fatty acid chains linked up with sn-glycerol-3-phosphate (D-glycerol). The bond between fatty acids and glycerol phosphate is an ester (shown as green color), (B) generic structure of phospholipids in archaea contains 'branched isoprenoid' units, linked up with sn-glycerol-1-phosphate (L- glycerol) via ether linkages, shown as red color. " $n$ " represents generic number for the isoprenoid or fatty acid units.

What is a plausible explanation for the formation of these two forms of glycerol phosphates (both sn-glycerol-1-phosphate and sn-glycerol-3-phosphate) between the major domains of life? An answer may lie in their biochemical synthesis. Glyceraldehyde3-phosphate dehydrogenase $\left(\mathrm{G}_{3} \mathrm{PDH}\right.$, hereafter) is a dehydrogenase enzyme that directs/catalyzes the biosynthesis of sn-glycerol-3-phosphate in eukaryotes and bacteria, whereas glyceraldehyde-1-phosphate dehydrogenase $\left(G_{1} P D H\right)$ is responsible for the synthesis of $s n$-glycerol-1-phosphate in archaea. It is an open question as to which form of glycerol phosphate existed first in biology: sn-glycerol-1-phosphate may have preceded sn-glycerol-3-phosphate (or vice versa), or both may have co-existed [35]. This feeds into a larger question that relates to the issue of a 'cenancestor' (defined as the ancestor species from which all modern organisms plausibly evolved): was it archaeal or was it bacterial? Both the $\mathrm{G}_{3} \mathrm{PDH}$ and $\mathrm{G}_{1} \mathrm{PDH}$ dehydrogenases and their presence in the cenancestor could plausibly be a cause of the diversification of archaea and bacteria [35]. 
Furthermore, the stereospecificity of lipids found in archaea and their unique structure has been hypothesized to be more stable in extreme environments, providing the organism better chances of survival [37]. However, archaea are also present in mesophilic (growing in moderate temperatures) and neutrophilic environments (living in neutral environments e.g., $\mathrm{pH}=6.5-7.3$ ) where the significance of a chemical variation in cell membrane composition is lessened [38]. With these points in mind, there are three hypotheses that attempt to explain the plausible origin of sn-glycerol-1-phosphate and sn-glycerol-3-phosphate cell membranes [35].

The first hypothesis posits the prebiotic synthesis of glycerol phosphate in a non-chiral fashion on a surface that would have then become the "first acellular metabolists" [38-40]. Due to non-chiral synthesis both sn-glycerol-1-phosphate and sn-glycerol-3-phosphate would have been used in phospholipid syntheses at the initial stages of the formation of cell membranes. Later, the organisms could plausibly evolve their respective enzymes $\left(\mathrm{G}_{1} \mathrm{PDH}\right.$ or $\left.\mathrm{G}_{3} \mathrm{PDH}\right)$ to catalyze the reduction of DHAP for specific glycerol phosphate, either sn-glycerol-1-phosphate or sn-glycerol-3-phosphate. These primitive organisms would eventually evolve into eukaryotes via archaeal-bacterial symbiotic associations and the acquired membranes would have passed onto the eukaryotes.

The second hypothesis was presented by Martin and Russell [41] who favor a hydrothermal origin of life and, according to them, iron monosulphide bubbles around hydrothermal vents could be considered as the earliest cellular compartments. In this scenario, the origin of life and metabolic activities were more geochemically-driven and many chemical activities could be successfully carried out within the iron monosulphide bubbles. It has further been proposed that this cell-like entity could perform metabolic activities and, at a certain stage, even became capable of forming RNA and the associated necessary proteins, but still thrived on iron monosulphide bubbles to act as cellular compartment and support its developing membranes or simple compartments. In this scenario, the chirality of glycerol phosphate was selected much later than the origin of life and may have been done at random.

The third hypothesis suggests the formation of a lipid membrane during a pre-cell stage (Figure 3). This membrane was a racemic mixture of chiral ancient lipid molecules that over the course of time gave rise to enantiomeric lipids that would have selected for a specific handedness depending on the evolution of the organisms, and eventually would have replaced the racemic mixture of lipids [35,38-42].

The prebiotic synthesis of phospholipids has undergone further studies specifically concerning the issue of the symmetry breaking of phospholipids [43]. These experiments have discussed issues such as the generation of pure enantiomeric lipid compounds from chiral or achiral reactants or catalysts. According to this study, in the evolution and development of membrane systems, the enzymatic activity appears to be the main strategy to get enantiomeric pure lipid type molecules. The study further suggests that the occurrence of two genes encoding for $\mathrm{G}_{1} \mathrm{PDH}$ and $\mathrm{G}_{3} \mathrm{PDH}$ could be responsible for the buildup of an evolutionary tree. Evolution of these two specific genes would have been the potential source of evolution in the membranes. Gene encoding for $\mathrm{G}_{3} \mathrm{PDH}$ in eukaryotes may have originated from $\mathrm{G}_{3} \mathrm{PDH}$ gene that is found in archaea revealing that archaea might have originated earlier than eukaryotes [43]. Archaea and bacteria might have evolved separately, a suggestion based on their distinctively different genes coding for $\mathrm{G}_{1} \mathrm{PDH}$ and $\mathrm{G}_{3} \mathrm{PDH}$. A consequence of this hypothesis is that the catalytic biosynthesis pathways of homochiral sn-glycerol-1-phosphate or sn-glycerol-3-phosphate are more efficient than those that form racemic glycerol phosphate mixtures. Additionally, it is quite possible that both $\mathrm{G}_{1} \mathrm{PDH}$ and $\mathrm{G}_{3} \mathrm{PDH}$ would have emerged separately during evolution [43]. 

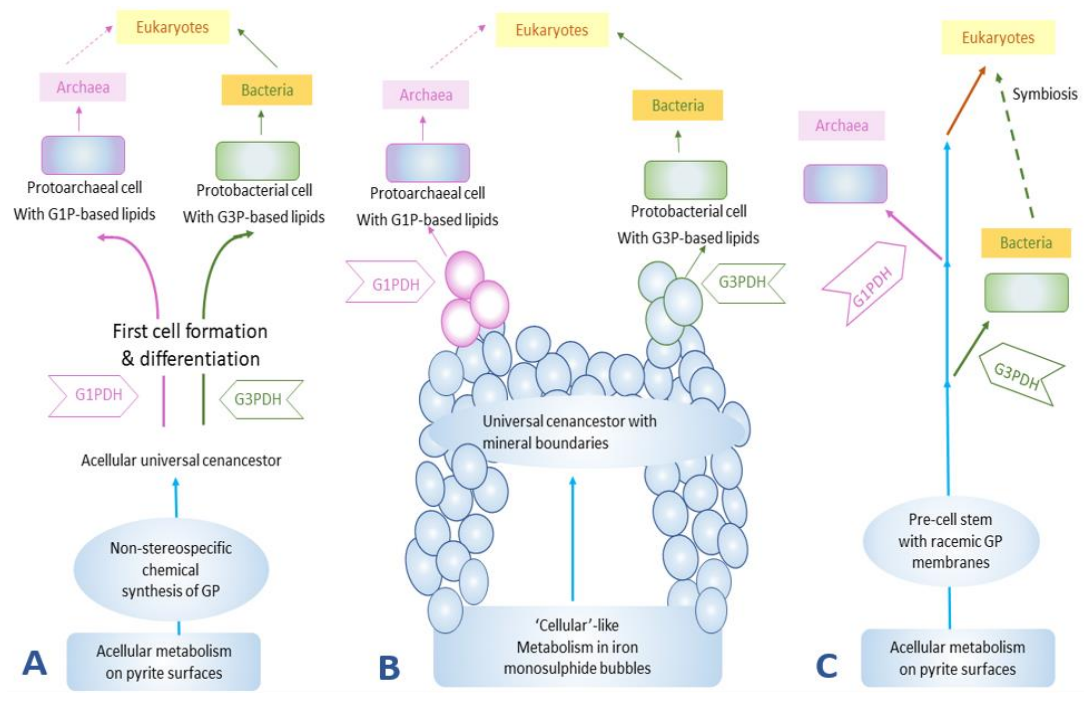

Figure 3. The formation of lipid membranes in primitive organisms: (A) the emergence of cellular life on pyrites, or more generally 'minerals' [40], (B) the emergence of life on monosulphide bubbles around hydrothermal vents [41], and (C) the non-stereospecific formation of the GP and the subsequent evolution of enzymes $\mathrm{G}_{\mathrm{I}} \mathrm{PDH}$ and $\mathrm{G}_{3} \mathrm{PDH}$ to catalyze the formation of stereospecific GP [42]. GP stands for glycerol phosphates, $\mathrm{G}_{1} \mathrm{P}$ stands for sn-glycerol-1-phosphate, and $\mathrm{G}_{3} \mathrm{P}$ stands for sn-glycerol-3-phosphate. This figure was redrawn and reprinted with permission from [35]; Copyright (c) 2004 Elsevier.

\section{Significance of Glycerol in the Biochemistry of Extremophiles}

Extremophiles are organisms that can thrive in severe environmental conditions such as extreme temperatures (both exceptionally cold or hot), extreme $\mathrm{pH}$ (highly acidic or alkaline), or other harsh environments such as presence of salts/oxidants/radiation and many other harsh conditions [44]. Extremophiles thriving in various harsh conditions help to understand the various forms of life and their adaptations. Moreover, studying extremophiles also has implications for the origin and evolution of early life on the Earth $[45,46]$ and thus these organisms are a subject of interest with relevance for this review article. This section will specifically highlight the significance of glycerol in the biochemistry of some extremophiles.

\subsection{Role of Glycerol in the Biochemistry of Microalgae, Archaea and Other Organisms}

Glycerol is a product of photosynthesis in the genus Dunaliella (red algae represented as $\mathrm{D}$. hereafter). $\mathrm{CO}_{2}$ is fixed to form glycerol $[47,48]$ in this process, as confirmed by the use of labeled ${ }^{14} \mathrm{CO}_{2}$. The speciation of ${ }^{14} \mathrm{CO}_{2}$-fixed products demonstrated most of the ${ }^{14} \mathrm{C}$ was present in glycerol. It was also found that glycerol's generation was directly proportional to an increase in salinity $[47,48]$. Studies with $D$. parva, D. tertiolecta $[47,49,50]$, and $D$. viridis $[51,52]$ revealed that the intracellular glycerol concentration is dependent on the salinity of the growth medium. D. parva cells were adapted to grow in concentration of $1.5-2 \mathrm{M} \mathrm{NaCl}$ and had about 2-2.2 $\mathrm{M}$ glycerol in the intracellular medium, whereas cells of $D$. salina grown in $4 \mathrm{M} \mathrm{NaCl}$ contained about $7.8 \mathrm{M}$ glycerol (same as $72 \%$ glycerol solution in water by weight) [53]. Figure 4 shows the natural habitat of the aforementioned halophilic organisms, also known as red algae.

A schematic diagram of the 'glycerol cycle' in the genus Dunaliella is represented as Figure 5A. The starting substrate is DHAP. Four specific enzymes catalyze the overall synthesis of glycerol, including (1) $\mathrm{NAD}^{+}$dependent dehydrogenase or DHAP reductase, (2) glycerol-3-phosphate phosphatase, (3) DHA reductase, and 4) DHA kinase [47]. In the presence of light, glycerol is synthesized via photosynthesis, followed by the Calvin cycle (the light independent phase of photosynthesis) and, in the absence of light, the starch in the organism is converted into glycerol $[47,54-56]$ (Figure 5). 

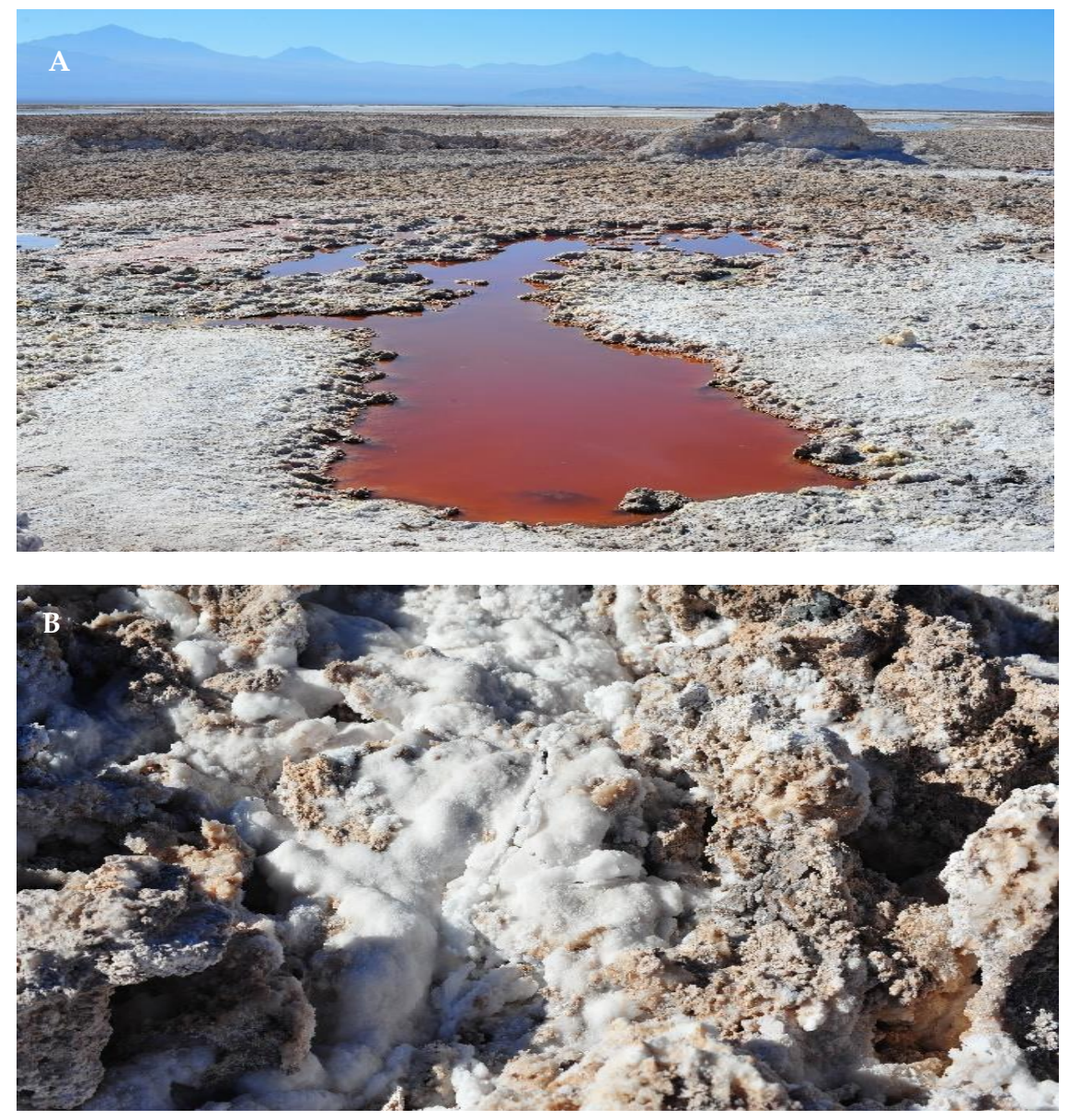

Figure 4. Images of Lake Chaxa: (A) a salt-flat lake in Chile wherein red algae impart a reddish hue to the lake, (B) higher salt contents and salt crusts that can easily be seen as large white deposits. This lake is the habitat of halophilic organisms including the red algae Dunaliella. These species thrive in high salt conditions, and the briny lake is an ideal habitat for these halophiles. Photo credit to Chris Hunkeler. Both images are licensed under the creative commons Attribution-Share Alike license.

Co-enzyme $\mathrm{NAD}^{+}$(nicotinamide adenine dinucleotide) assists in various metabolic reactions and exists in another form, $\mathrm{NADP}^{+}$, which undergoes reduction by accepting electrons and hydrogen (e.g., $\mathrm{H}^{-}$) atoms to form NADPH. NADH and NADPH (nicotinamide adenine dinucleotide phosphate) are hence the biochemical reducing agents that drive this reaction. ATP (adenosine triphosphate), also known as the 'energy currency' of life, is needed in the process, which hydrolyzes ATP into ADP (adenosine diphosphate) to release energy.

Enzymes such as glycerol-3-phosphate dehydrogenase and glycerol-3-phosphate phosphatase help with the catalytic conversion of glycerol from DHAP, followed by the re-conversion of glycerol to DHAP, which is catalyzed by DHA reductase and DHA kinase $[47,49,50]$. These cyclic processes are highly energy dependent and need ATP to sustain and complete the cycle. Different steps of the glycerol cycle could happen in different locations in the cell, owing to the distribution of various enzymes, for example, enzymes like glycerol-3-phosphate dehydrogenase and quite possibly glycerol-3-phosphate phosphatase are located in the chloroplasts whereas DHA reductase is located in the cytoplasm. However, the locations and distributions of enzymes such as glycerol-3-phosphate phosphatase and DHA kinase are uncertain and still under further scrutiny. In the presence of light, glycerol can be synthesized by the products of photosynthesis, whereas in the dark starch hydrolyzes into glycerol [47-56] (Figure 5A). 


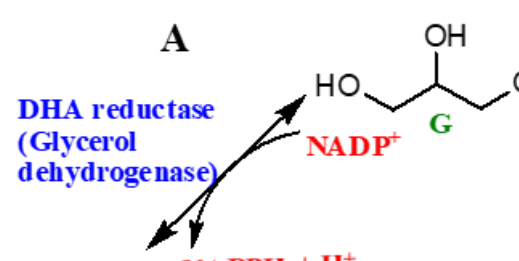

$\mathrm{NADPH}+\mathrm{H}^{+}$
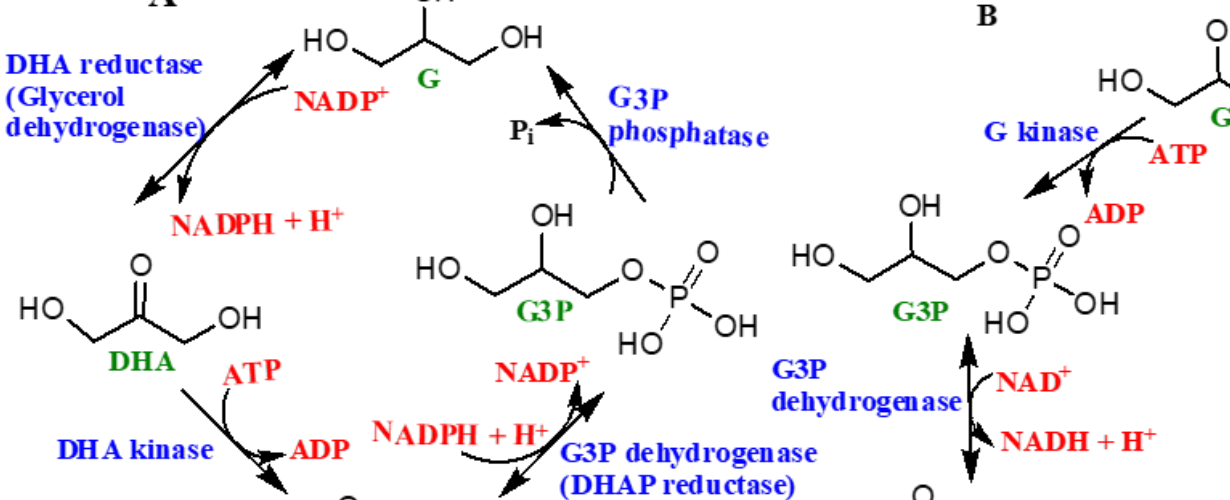

G3P

G3P

dehyd rogen ase $\mathrm{NAD}^{+}$

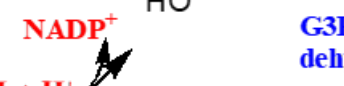

G3P dehydrogen ase<smiles>CP(=O)(O)OCC(=O)CO</smiles>

DHAP HO' 'OH

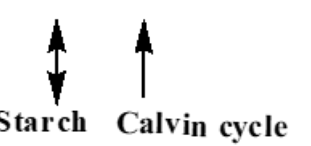

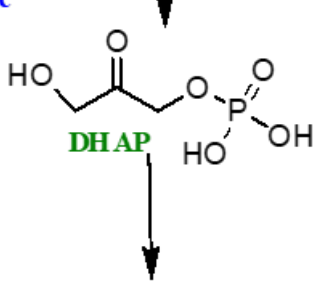

Further degrad ation
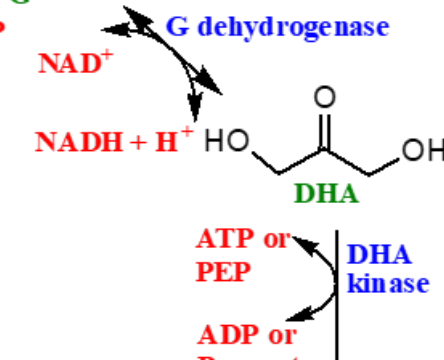

Pyruvate

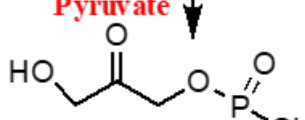

DHAP HO'

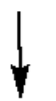

Further degradation

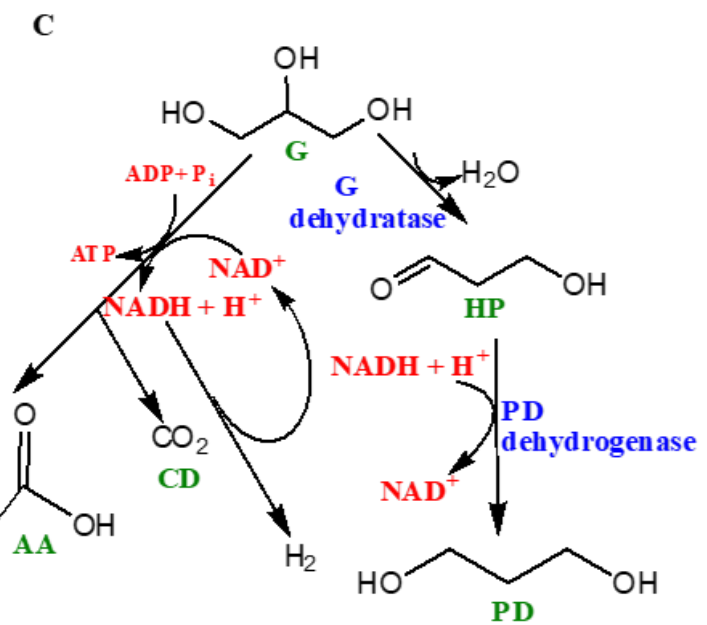

PD

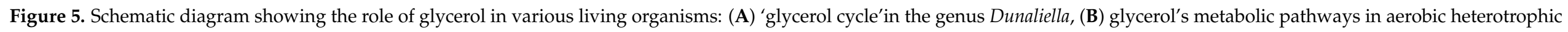

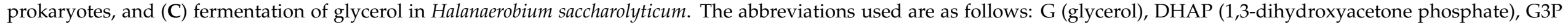

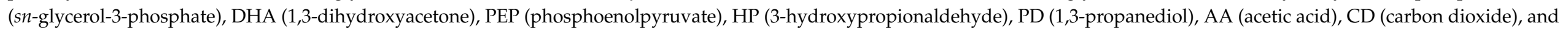

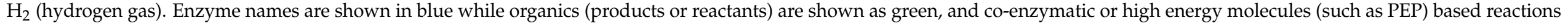
are shown as red. For more information see [47]. Figure reproduced, redrawn (with minor modifications) with permission from [47]; Copyright @2017 John Wiley and Sons. 
Glycerol is also consumed by prokaryotes such as halophilic aerobic archaea that may catabolize glycerol by two pathways (Figure 5B). One path involves the synthesis of sn-glycerol-3-phosphate and subsequent formation of DHAP [47]. The major enzymes involved include glycerol kinase, a potential sn-glycerol-3-phosphate ABC transport system, and glycerol 3-phosphate dehydrogenase $[47,57,58]$. Alternatively, glycerol first converts into DHA with the help of glycerol dehydrogenase enzyme [59]. The synthesized DHA can potentially get phosphorylated and subsequently fed into certain Embden-Meyerhof pathways (a form of glycolytic pathway) or converted into metabolic intermediates including sn-glycerol-1-phosphate, which make up the backbone of archaeal phospholipids [47,58,59].

Certain halophilic archaea such as Halanaerobium saccharolyticum (and many others) have been demonstrated to generate energy by the fermentation of glycerol through its conversion into acetate, $\mathrm{H}_{2}$ and $\mathrm{CO}_{2}$ [47]. This is an anaerobic pathway. Figure $5 \mathrm{C}$ shows the fermentation of glycerol in Halanaerobium saccharolyticum. The aforementioned features of glycerol are attributed to its simplicity and excellent solubility in water, thus making it an excellent source of carbon for these organisms. A majority of halophilic bacterial species were found to be highly dependent on glycerol for nutrition [57]. Halophilic archaea consume glycerol by two different pathways: phosphorylation to sn-glycerol-3-phosphate and eventual conversion into DHAP and glycerol conversion into DHA. Both paths require their own sets of enzymes [58,59].

Another fascinating feature of glycerol is its help in maintaining the osmotic pressure in algae, where it acts as a solvent to regulate cellular metabolism and maintains enzymatic and other cellular activities under these saline concentrations [47-49]. This special feature of glycerol is seen in extremophiles living in highly saline environments.

There are so many other organisms that thrive on glycerol by consuming it as a nutrient. One such remarkable is Anaerobium acetethylicum, a strictly anaerobic, mesophilic bacterium which converts glycerol into useful compounds such as ethanol and hydrogen [60-62].

Certain fungal xerophiles such as Aspergillus penicillioides and Xeromyces bisporus are known to thrive in high solute environments and/or alternatively at very low water availability, by retaining high levels of glycerol for their osmotic adjustments [63,64]. Furthermore, in such species, glycerol is also known to facilitate the xerophile spore germination [64]. Similarly, halotolerant yeast Debaryomyces hansenii is also known to produce copious amounts of glycerol under increased saline concentrations [65]. This behavior is similar to that of genus Dunaliella of the red algae.

It is important to mention here that the utilization of glycerol as a substrate to derive energy and nutrients by various organisms has been documented previously in the scientific literature already available. Furthermore, the discussion of how non-extremophiles consume glycerol is beyond the scope of the current paper. The primary focus of this review article is extremophiles, owing to their relevance from an evolutionary viewpoint where they lie close to the root of the tree of life.

\subsection{Plausible Commercial Synthesis of Glycerol from Algae and Other Organisms}

As discussed above, algae such as Dunaliella can potentially produce substantial amounts of glycerol. This production can be used for the industrial production of glycerol and other relevant organics on commercial scales [47-49]. Even though the raw materials for glycerol synthesis include cheap and simple substances such as saline solutions, $\mathrm{CO}_{2}$, and sunlight, the process has yet to meet with success [49]. Similarly, D. tertiolecta is also used to synthesize glycerol. Such syntheses reactions could be extremely beneficial not only because of the cheap raw materials necessary for this reaction, but this pathway could also serve as a route to $\mathrm{CO}_{2}$ fixation.

Another way of producing glycerol industrially is by using yeast for the commercial preparation of glycerol in microbial fermentation. Glycerol production by employing yeast species such as Saccharomyces cerevisiae was discovered by Louis Pasteur [66]. Since then, significant developments have been achieved in improving the yields from living cells of this yeast and hence this phenomenon is well studied in this organism. Glycerol is 
synthesized by using the glycolysis intermediate DHAP in two consecutive reactions steps and is catalyzed by enzymes including glycerol-3-phosphate dehydrogenase and glycerol3-phosphate phosphatase [67]. Glycerol production by Saccharomyces cerevisiae and other organisms such as Candida glycerinogenes and Candida krusei (yeasts), Dunaliella tertiolecta and Dunaliella bardawil (algae), Synechococcus elongatus (cyanobacteria), and many other organisms has been extensively reviewed [67]. These techniques are indeed the fruitful consequence of well-studied phenomena such as the mechanism of glycerol metabolism and its transportation in organisms [67].

\subsection{Glycerol and its Phosphorylated Derivatives as Solutes in Thermophiles}

Glycerol and its phosphorylated derivatives play an important role in the biochemistry of extremophiles such as thermophiles (having optimum growth temperatures between $65{ }^{\circ} \mathrm{C}$ and $80^{\circ} \mathrm{C}$ ), hyperthermophiles (having optimum growth temperatures above $80^{\circ} \mathrm{C}$ ), and halophiles including moderate halophiles (having higher growth rates in media containing between $0.5 \mathrm{M}$ and $2.5 \mathrm{M} \mathrm{NaCl}$ ) and extreme halophiles (having higher growth rates in media containing over $2.5 \mathrm{M} \mathrm{NaCl}$ ) [68,69]. It is intriguing that many hyperthermophiles, moderate and extreme halophiles, and other species accumulate 'compatible' or 'favorable' small organic compounds, commonly known as 'compatible solutes' or 'osmolytes' [55,70]. Such solutes can either be taken from the surrounding environments or synthesized within cells [68]. Such solutes not only help the organism keep up with balancing osmotic pressure but also do not negatively interfere with cellular activities [55]. They also provide stability in extreme conditions such as extreme low or high temperatures or an abundance of free radicals for instance caused by radioactivity [70-74].

One such remarkable solute is diglycerol phosphate, a phosphorylated derivative of glycerol that consists of two units of glycerol linked by a bridging phosphate group (Figure 6). This compound is found in species Archaeoglobus fulgidus (a halophile) and it helps the organism manage salt stress $[68,75,76]$. It is also possible that diglycerol phosphate and other molecules also help the organism maintain protein stability under harsh conditions [68]. In addition to providing stability to the proteins [77], studies have shown that diglycerol phosphate helps by protecting a specific enzyme-lactate dehydrogenasefrom harsh heat. Another related derivative called glucosyl glycerol (a sugar derivative of glycerol) is also known to provide stability and support to thermophiles [78].
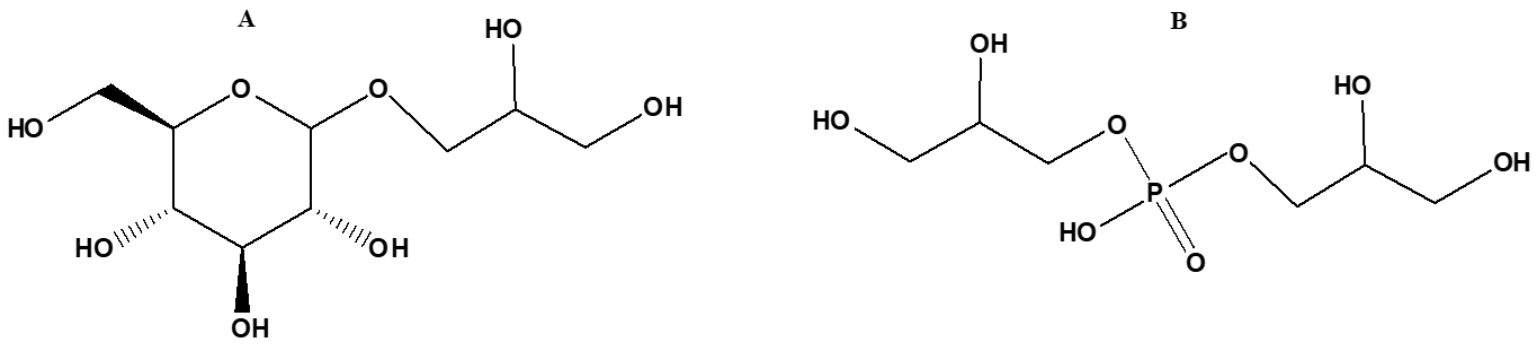

Figure 6. Important derivatives of glycerol in thermophiles as discussed in the text [78]: (A) glucosyl glycerol, which is a non-phosphorylated derivative of glycerol and is formed by the condensation reaction of glycerol with glucose via glycosidic bond and (B) diglycerol phosphate, formed by the condensation reaction between two units of glycerol and a phosphate group.

\section{Prebiotic Origin of Glycerol}

Having now established multiple roles for glycerol in biochemistry-roles ranging from lipid membranes to metabolism to a cytoplasm component-we see that glycerol is important across a range of biochemical functions. To this end, understanding the prebiotic origin of glycerol may be relevant for understanding how this important molecule was first utilized by life. One of the first questions for the origin/prebiotic synthesis of glycerol is the 'site of origin'. For instance, the environments that can lead to the formation of glycerol rely on reduced carbon species (as glycerol is even more reduced in oxidation 
state than formaldehyde) and generally UV-rich sources for polymerization. This is in contrast to the formation of fatty acids, which has generally been considered as a product of hydrothermal systems (which are generally $\mathrm{H}_{2} \mathrm{O}$ and hydrocarbon-rich) or Fisher-Tropsch type reactions [79-85]. Therefore the combination of such systems is questionable owing to the significant difference between these environments, such as pressure, temperature, and $\mathrm{pH}$.

There have been some successful demonstrations of plausible prebiotic syntheses of glycerol. For instance, the classical formose reaction has also been reported to produce certain chemical derivatives of glycerol such as 2-hydroxymethyl glycerol, along with pentaerythritol. These particular formose branch reactions were observed when high concentrations of $\mathrm{CH}_{2} \mathrm{O}$ solution (about $8 \mathrm{M}$ ) were used alongside $0.62-1.63 \mathrm{M}$ alkaline solutions $\left(\mathrm{NaOH}\right.$ or $\left.\mathrm{Na}_{2} \mathrm{CO}_{3}\right)$ and the reaction mixture was irradiated with $\mathrm{UV}$ light [86]. The formose reaction is often employed in prebiotic chemistry due to its production of sugars, which are key constituents of nucleic acids.

Most experiments that demonstrate the production of glycerol have employed socalled "astrophysical conditions". These conditions take organics and ice at cold temperatures $(<20 \mathrm{~K})$, and subject them to irradiation. For instance researchers have identified glycerol in UV photo-processed icy mixtures [87], which serve to mimic astrophysical environments that may produce organic compounds. However, at that time glycerol was disregarded as a contaminant in the methanol during the extraction process. Follow-up studies subsequently produced similar results and the glycerol was identified as a product under the afore-mentioned reactions of icy mixtures [88]. Furthermore, glycerol and glyceric acid were also produced as a consequence of $U V$ irradiation of an $\mathrm{H}_{2} \mathrm{O}: \mathrm{CH}_{3} \mathrm{OH}: \mathrm{NH}_{3}: \mathrm{HCN}$ (20:2:1:1) ice mixture [89]. When similar reaction conditions (UV catalyzed, icy reaction mixture of methanol and ammonia at $80 \mathrm{~K}$, also used in $[87,88]$ ) once again produced glycerol, the use of isotopically-labeled ices finally confirmed the presence of glycerol as a product [90].

Another attempt showed a cascade of chemical reactions, starting from simple precursor molecules such as $\mathrm{HCN}, \mathrm{CH}_{2} \mathrm{O}$, and $\mathrm{H}_{2} \mathrm{~S}$, with the final products including glycerol. The reactions (specifically the final steps) were catalyzed by UV light [91]. Quite recently, the abiotic synthesis of glycerol has been reported by exposing methanol-based, model interstellar ices to ionizing radiation [92]. The reaction conditions in [92] simulate astrophysical environments that were also used previously $[87,88,90]$ and reaffirm the idea of formation of glycerol under interstellar icy environments.

In addition to glycerol, the compounds glyceric acid, glycolaldehyde, DHA, and others were obtained after UV irradiation of an $\mathrm{H}_{2} \mathrm{O}:{ }^{13} \mathrm{CH}_{3} \mathrm{OH}: \mathrm{NH}_{3}$ (10:3.5:1) ice mixture [93]. In these experiments, glycerol was probably formed by the combination of $3 \mathrm{CH}_{3} \mathrm{OH}$ molecules as $\mathrm{CH}_{2} \mathrm{OH}$ radicals. Since $\mathrm{H}_{2} \mathrm{CO}$ is one of the most abundant photoproducts of $\mathrm{CH}_{3} \mathrm{OH}$ in ices, it is also possible that some of the glycerol is formed via reactions involving $\mathrm{H}_{2} \mathrm{CO}$.

Another work employed laser-induced high-energy (laser induced dielectric breakdown plasma) chemistry combined with a $\mathrm{TiO}_{2}$ catalyst and demonstrated the synthesis of glycerol and diglycolic acid along with a mixture of pentoses (threose, arabinose, ribose, and xylose). Subsequent gas chromatography-mass spectroscopic (GC-MS) analysis after derivatization by silylation also identified glycolaldehyde along with the above-mentioned products. The authors of this study reported this experiment to be relevant to the impact of an icy extraterrestrial object on the early Earth [94].

Recently, the formation of organics such as glycolaldehyde and ethylene glycol on icy dust grains through a non-energetic atomic addition reaction between $\mathrm{H}$ atoms and $\mathrm{CO}$ molecules has been shown [95]. This process is reported to promote surface chemistry during the 'CO-freeze out stage' in dense icy cores of dust grains in the interstellar medium. In this process, the chemical interactions between different reactive intermediates produced as a consequence of hydrogenation of $\mathrm{CO}$ ice also form glycerol. The authors have also 
suggested a tentative identification of glyceraldehyde by similar interactions [95]. Such reactions show more potential in forming more complex sugars and alcohols.

The above mentioned experiments under simulated astrophysical environments, i.e., very low temperatures (typically, $<20 \mathrm{~K}$ ), very low pressures (typically, $<10^{-8} \mathrm{mbar}$ ), and high doses of ionizing radiation (typically, UV, extreme UV, or X-ray photons, high-energy electrons, or high-energy protons) plausibly show a universal process in space for the formation of glycerol. To this end, extraterrestrial and terrestrial sources may have both been sources of glycerol on the early Earth. If glycerol plays a significant role in the origin of lipid compounds, and hydrothermal systems are the major sites for the latter (lipids), how would glycerol have been provided for such reactions? This question still needs to be resolved.

\section{Extraterrestrial Sources of Glycerol}

Carbonaceous chondritic meteorites are pieces of asteroids that have remained relatively unaltered since the early formation of the Solar System. Many chondrites are found to be rich $(\sim 2 \%)$ in organic compounds and many organics extracted from meteorites are prebiotically relevant, which suggests meteorites may have played a significant role in the origin of life by providing with an inventory of organics. Glycerol has been identified in the organic mixtures extracted from carbonaceous chondrites [96], where it is among the most abundant of sugar-like organic compounds with at least three carbons (present at about $100 \mathrm{ppb}$ ). Similarly, it has been identified alongside several other polyols in the water extracts of the carbonaceous chondrites Murchison and Murray [97].

It has been suggested that interstellar $\mathrm{CH}_{2} \mathrm{O}$ chemistry might have been involved in the production of glycerol and other relevant polyols [98,99] (as above, and see Table 2 of [99]). The separation and identification of glycerol from meteoritic samples shows that it is somewhat easier to chemically synthesize glycerol from abiotic processes. Its plausible formation and relative stability in meteorite parent bodies make it possibly the most commonly occurring 'polyol' compound. These studies also suggest that its occurrence in meteorites is more common than sugars, suggesting glycerol was plausibly abundant on the early Earth. However, the chemical synthesis of glycerol from its precursors within meteorite parent bodies has yet to be demonstrated.

The successful synthesis of glycerol and other organics under simulated astrophysical environments highlight a plausible explanation for finding a plethora of organics in various meteoritic extracts. These organics were synthesized either in astrophysical ice that later accreted as part of an asteroid, or were synthesized in the asteroid itself (for instance, via aqueous alteration).

Regardless, extracts of meteorites demonstrate glycerol was delivered to the surface of the Earth via meteorites. It is possible that glycerol (and other polyols or even sugars along with other organics) may have produced abiotically in the cosmos and meteorites would have brought such compounds on the early Earth.

\section{Biochemical Derivatives of Glycerol and their Prebiotic Origin}

In this section, the prebiotic origin of some biochemical derivatives of glycerol will be discussed. We presume the presence of glycerol in such a discussion. Some of the most important derivatives that are relevant to the origin of life and to chemical evolution include acylglycerols, glycerol-phosphates, and phospholipids, as well as the oxidation products of glycerol and their phosphorylated derivatives.

\subsection{Acylglycerols}

These compounds, also referred to as simple or incomplete lipids, are essential components of cell membranes. These can form as the condensation products of a reaction heated to dryness between glycerol with fatty acids, which is an esterification process known as acylation. The acylation products are named based on how many fatty acid groups they contain, from monoacylglycerols to diacylglycerols to triacylglycerols (Figure 7). 

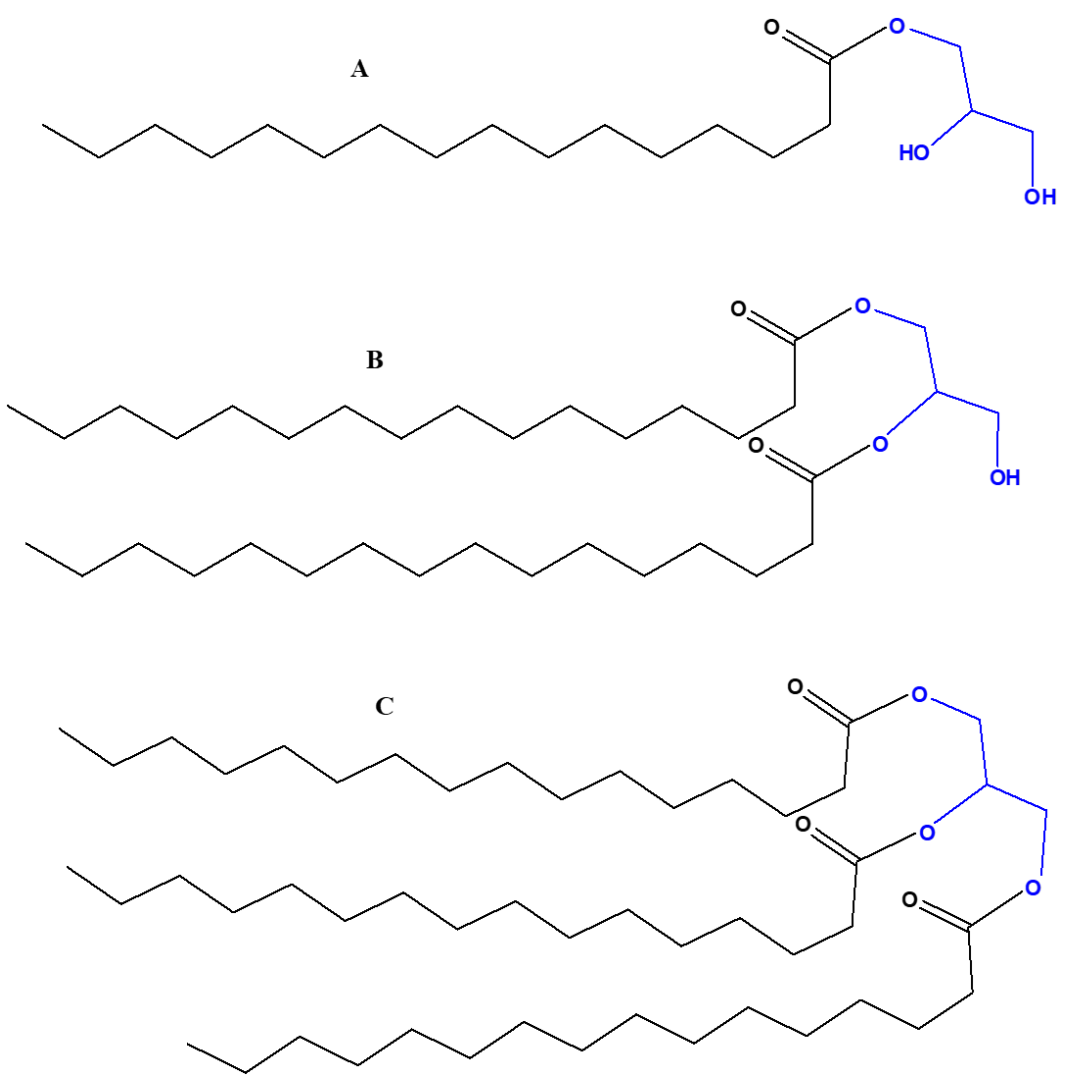

Figure 7. Various types of palmitoylglycerols obtained by heating ammonium palmitate with glycerol: (A) monopalmitoylglycerol, (B) dipalmitoylglycerol and (C) tripalmitoylglycerol, as discussed in [100]. Blue color shows glycerol linked with fatty acid chains through acylation.

Hydrothermal systems—one of the proposed sites for the origin of life [79-85]—may have been a site for the prebiotic syntheses of acylglycerols, wax esters, and other associated ester biomolecules. This is attributed to the fact that at high temperatures and pressures water has a zero-dipole moment [81], and hence acylation is more favorable. Moreover, the degree of $\mathrm{H}$-bonding and the dielectric constant also decrease under such conditions. All these attributes make water behave as non-polar solvent, thus by making hydrothermal sites suitable for the prebiotic syntheses of fatty acids and lipid type molecules.

Condensation reactions are also known to be carried out in the presence of condensation agent such as cyanamide. Cyanamide-based condensation reactions were suggested as one of the first reported prebiotic experiments [100]. Oró and colleagues obtained various forms of acylglycerols, from mono-, di-, and even tri-palmitoyl glycerol derivatives, by heating ammonium palmitate with glycerol at $60-100^{\circ} \mathrm{C}$ [100]. Other condensation agents and reactions have been explored extensively since then [101-104]. Hydrothermal sites are also considered suitable for similar condensation reactions [105]. The successful prebiotic syntheses of acylglycerols have been reported under hydrothermal conditions [106,107]. These reported syntheses are so far the most reliable source of acylglycerols. The summary of prebiotic syntheses of lipid type molecules has been reviewed which discusses the possibility of various sources of lipid type compounds, their plausible origin, and catalysts or condensation agents that aid such reactions $[108,109]$.

Acylglycerols not only help in forming the cell membranes but also contribute to their stabilities. In a study, the formation and relative stabilities of cell membranes were observed by using membranes consisting of various fatty acids (e.g., with hydrocarbon chain lengths between 8 and 18 carbons) mixed with their respective glycerol monoacyl amphiphile derivatives (GMAs) [110]. The key features studied were critical vesicle concentration $(\mathrm{CVC})$, encapsulation, and effects of temperature on membrane stability. During the study it was found that the membrane stability was greatly influenced by hydrocarbon chain 
lengths and by the presence of GMAs. Moreover, the encapsulation capability of the cell membranes/vesicles also increased as a function of the fatty acid chain length. The research concluded that GMAs can remarkably increase the stability of mixed amphiphile vesicle membranes [110] and, moreover, also highlights the significance of simple lipid type compounds and chain lengths of the fatty acids in the origin and evolution of cellmembranes.

\subsection{Glycerol Phosphates}

The phosphorylated derivatives of glycerol play a central role in cellular respiration and cell structure. Glycerol phosphates have been successfully synthesized under prebiotic conditions. Glycerol phosphate synthesis has been reported by condensing ammonium phosphates with both glycerol and condensation agents at $85^{\circ} \mathrm{C}$. In this study, aqueous solutions $(0.2 \mathrm{~mL})$ containing glycerol $(5 \mu \mathrm{moles})$ and ammonium dibydrogen phosphate ( 5 or $15 \mu$ moles) were prepared and $50 \mu$ moles of urea (or other condensation agents such as cyanamide) was added to the solution. The reaction solution was then evaporated under nitrogen to dryness and subsequently heated for $16 \mathrm{~h}$ at $85^{\circ} \mathrm{C}$. The yield of the glycerol phosphates was about $30 \%$ [111].

The prebiotic synthesis of glycerol phosphates under simulated hydrothermal conditions and at low $\mathrm{pH}$ of about 1-2 has also been reported [112]. Furthermore, various non-aqueous solvents have also been tried to improve the yield and efficiency of the reactions [113-115]. In addition, high energy phosphates such as diamidophosphate (DAP) and cyclic trimetaphosphate are reported to spontaneously phosphorylate glycerol even at room temperature [116] (Table 1 and Figure 8). The structures of various forms of inorganic phosphorus sources that have been employed in the phosphorylation reactions is given in Figure 8.

Table 1. Prebiotic synthesis of glycerol phosphates.

\begin{tabular}{|c|c|c|c|c|}
\hline${ }^{1}$ P Source & Catalyst/Condensation Agent & Reaction Conditions & ${ }^{2}$ Yields & Ref. \\
\hline $\mathrm{NH}_{4} \mathrm{H}_{2} \mathrm{PO}_{4}$ & urea $/ \mathrm{NH}_{4} \mathrm{Cl} /$ cyanamide & heat at $85^{\circ} \mathrm{C}, 16 \mathrm{~h}$ & $30 \%$ & [111] \\
\hline $\mathrm{H}_{3} \mathrm{PO}_{4}$ & wide range of clays \& minerals & $\begin{array}{l}\text { hydrothermal conditions, } \\
\qquad 100-200{ }^{\circ} \mathrm{C}\end{array}$ & $1 \%$ & [112] \\
\hline $\begin{array}{c}\mathrm{TMP} \\
\mathrm{NaH}_{2} \mathrm{PO}_{4}\end{array}$ & Silicates & formamide, DES of glycerol \& choline chloride, $85^{\circ} \mathrm{C}$ & $10-90 \%$ & [113] \\
\hline $\begin{array}{l}\mathrm{NaH}_{2} \mathrm{PO}_{4} \\
\text { monetite, } \mathrm{H}_{3} \mathrm{PO}_{3} \\
\text { struvite }\end{array}$ & - & $\begin{array}{c}\text { DES of choline chloride \& urea, } \\
\text { heat } 60-80^{\circ} \mathrm{C}\end{array}$ & $10-65 \%$ & [114] \\
\hline $\begin{array}{l}\mathrm{Na}_{2} \mathrm{HPO}_{4} \\
\mathrm{P} \text { minerals }\end{array}$ & - & $\begin{array}{l}\text { UAFW, wet-dry cycles, } \\
65 \text { or } 80^{\circ} \mathrm{C}\end{array}$ & $10-50 \%$ & [115] \\
\hline DAP & imidazole & room temp- $50{ }^{\circ} \mathrm{C}$, paste reactions & $12-60 \%$ & [116] \\
\hline $\begin{array}{l}\text { struvite, } \\
\text { monetite }\end{array}$ & - & $75^{\circ} \mathrm{C}$, heating leading to dryness & $28 \%$ & [117] \\
\hline
\end{tabular}

\footnotetext{
${ }^{1} \mathrm{P}$ source means phosphorus source. ${ }^{2}$ The yields of the glycerol phosphates were based on various ways the calculations and analyses were performed, e.g., $[113,114,117]$ the yields were calculated by peak integration method of ${ }^{31} \mathrm{P}-\mathrm{NMR}$ while in other reported literature HPLC/LCMS were used [112,115]. Other employed techniques were ${ }^{13} \mathrm{C}-\mathrm{NMR},{ }^{1} \mathrm{H}-\mathrm{NMR}$ and ${ }^{31} \mathrm{P}-\mathrm{NMR}$ [78] and quantification and analysis were also done by gas chromatography, gas chromatography coupled to mass spectrometry, and paper chromatography [111]. DES stands for deep-eutectic solvent, TMP is trimetaphosphate, and DAP is diamidophosphate.
}

\subsection{Minerals and Condensation Agents in the Prebiotic Syntheses of Glycerol Phosphates}

Minerals such as clays may have played a significant role in prebiotic catalysis reactions. The prebiotic synthesis of glycerol phosphates under hydrothermal conditions has been reported to be catalyzed by several minerals, and specifically by clay minerals [112]. Minerals such as offretite, garnet, hematite, and quartz, and clays such as kaolinite and perlite have been reported to successfully catalyze the formation of glycerol phosphates at $\mathrm{pH}=1-2$, and at temperatures of $100-200{ }^{\circ} \mathrm{C}$. The yields of the products were doubled in experiments with minerals present in contrast to mineral-free experiments. 
Further research demonstrated that the yields of glycerol phosphates are remarkably increased when silicates (quartz sand and the clay kaolinite) are used [113]. The yields were calculated by ${ }^{31} \mathrm{P}-\mathrm{NMR}$ studies and reached about $90 \%$ in the presence of silicates. However, these experiments also employed non-aqueous solvents that likely strongly affected reaction efficiency. The synthesis of glycerol phosphates has also been seen to be improved by using condensation agents such as urea or imidazole $[111,116]$.
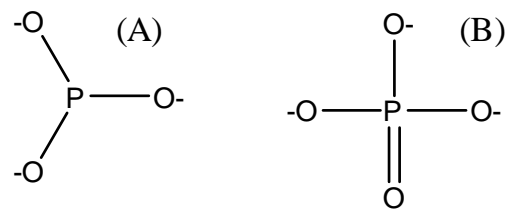<smiles>O=P1(O)OP(=O)(O)OP(=O)(O)O1</smiles><smiles>NP(N)(=O)[O-]</smiles>

Figure 8. Structures of various forms of inorganic phosphorus compounds discussed in the text: (A) phosphite ion which is a reduced form of phosphorus, found in meteorites and in other natural sources, (B) orthophosphate ion, (C) cyclotrimetaphosphate, a high-energy condensed phosphate, and (D) diamidophosphate, which is a form of high-energy phosphate.

\subsection{Role of Non-Aqueous Solvents in the Prebiotic Syntheses of Glycerol Phosphates}

The phosphorylation of biomolecules is thermodynamically an 'uphill' process [118]. It involves a dehydration step which is usually achieved by heating. Consider the reaction [118]:

$$
\mathrm{R}-\mathrm{OH}+\mathrm{HO}-\mathrm{PO}_{3}{ }^{2-} \rightarrow \mathrm{R}-\mathrm{O}-\mathrm{PO}_{3}{ }^{2-}+\mathrm{H}_{2} \mathrm{O}
$$

where $\mathrm{ROH}$ stands for a generic organic with an $\mathrm{OH}$ group such as an alcohol or sugar. The reaction shown is endergonic, requiring energy. This reaction is unfavorable from the thermodynamics viewpoint since the release of water as a product within an aqueous environment is unfavorable (via Le Chatelier's principle, as water is already the solvent in this reaction). This problem or issue in prebiotic chemistry has been referred to as the "water problem". The challenge of condensation reactions occurring in water is overcome through many ways such as using minerals as catalysts together in dry conditions [112,113] or using condensation agents $[111,116]$. One additional approach is the use of non-aqueous solvents.

Various prebiotic solvents have been employed to promote the phosphorylation of glycerol. Herein, we present some key non-aqueous solvents that are particularly relevant to the glycerol phosphorylation.

\subsection{Formamide as a Prebiotic Solvent}

Schoffstall was one of the first researchers to discuss the prebiotic significance and relevance of formamide and demonstrated how condensation reactions proceed using formamide as a solvent $[119,120]$. Nucleotides and their derivatives were formed when nucleosides were heated to react with various phosphorus sources. The major reaction products of adenosine were $2^{\prime} 3^{\prime}$ and $5^{\prime}$-AMPs, $2^{\prime}, 5^{\prime}$ and $3^{\prime}, 5^{\prime}$-ADPs and $2^{\prime}, 3^{\prime}$-cyclic AMP. The rate of phosphorylation reactions in formamide exceeded $50 \%$ (after 15 days at $70{ }^{\circ} \mathrm{C}$ ) [119]. In another study, simple organic alcohols and nucleosides were reported to undergo reaction with formamide to yield formate esters. The ester bond formation was somewhat slow at $100^{\circ} \mathrm{C}$ but occurred more rapidly at $130^{\circ} \mathrm{C}$ [120]. Building on this work, a prebiotic route for nucleoside phosphorylation using inorganic phosphates and borates as catalysts has also been suggested [121]. The extensive work by the Saladino group has shown that formamide works well as a 'prebiotic solvent' $[122,123]$. Liquid formamide also produces a plethora of organics when irradiated with high-energy protons in the presence of various catalysts. The products alongside glycerol included nucleobases, organic carboxylic acids, and even fatty acids [124] during this irradiation process. 
Recently, it has been shown that the phosphorylation of glycerol increases remarkably in the presence of formamide as a solvent [113]. However, all these cases assume the presence of pools of formamide, which may be unlikely as formamide hydrolyzes to ammonium formate at relatively low temperatures when water is abundant [125].

\subsection{Deep Eutectic Solvents}

Deep eutectic solvents (DES) are a class of ionic liquids wherein the mixing of two components creates a eutectic liquid with a "deep" melting point, such as 2.5:1 glycerol and choline chloride, and 2:1 urea and choline chloride. DESs exhibit unique features such as low volatility and stability over a wide range of temperatures [126-129]. DESs have also been employed to study the phosphorylation reactions of glycerol. The phosphorylation of glycerol was carried out in a glycerol and choline chloride DES using various phosphorus sources such as trimetaphosphate (TMP), monetite $\left(\mathrm{CaHPO}_{4}\right)$, struvite $\left(\mathrm{NH}_{4} \mathrm{MgPO}_{4} \cdot 6 \mathrm{H}_{2} \mathrm{O}\right)$, and $\mathrm{NaH}_{2} \mathrm{PO}_{4}$. Silicates were added as catalysts for the reactions (Table 1 and Figure 8) [113]. The other DESs that have been used for glycerol phosphorylation include urea and choline chloride mixture. This DES has specifically been established as an important ionic solvent [114]. It is plausible that the phosphorylation of glycerol (and other organics) in this DES may be prebiotically relevant [114] as eutectic melts of urea and choline chloride can be formed by drying these mixtures $[114,130,131]$ and, furthermore, urea has been identified as a prominent product in the classical Miller-Urey experiments [131,132].

Both phosphite as well as phosphate esters of glycerol have been prepared using this DES [114]. Quite recently, another interesting semi-aqueous solvent has been utilized: a mixture of urea, ammonium formate, and water (with initial molar ratios of 1:2:4 and hereafter, UAFW). The mixture is mixed and heated at $65^{\circ} \mathrm{C}$ in a sealed container until a clear, transparent liquid is formed. This liquid is a mixture of formamide, urea, ammonium formate, and water [115], where the formamide forms from ammonium formate condensation.

Glycerol phosphates have been efficiently prepared in the UAFW, which has also been shown potential to phosphorylate nucleosides such as adenosine and uridine. Phosphorus minerals such as hydroxylapatite $\left(\mathrm{Ca}_{10}\left(\mathrm{PO}_{4}\right)_{6}(\mathrm{OH})_{2}\right)$, struvite, brushite $\left(\mathrm{CaHPO}_{4} \cdot 2 \mathrm{H}_{2} \mathrm{O}\right)$, and newberyite $\left.\mathrm{Mg}\left(\mathrm{PO}_{3} \mathrm{OH}\right) \cdot 3 \mathrm{H}_{2} \mathrm{O}\right)$ were capable of phosphorylating the organics quite efficiently in the UAFW solvent [115], and presumably would also phosphorylate glycerol. The various structural components of the DESs are shown in Figure 9.
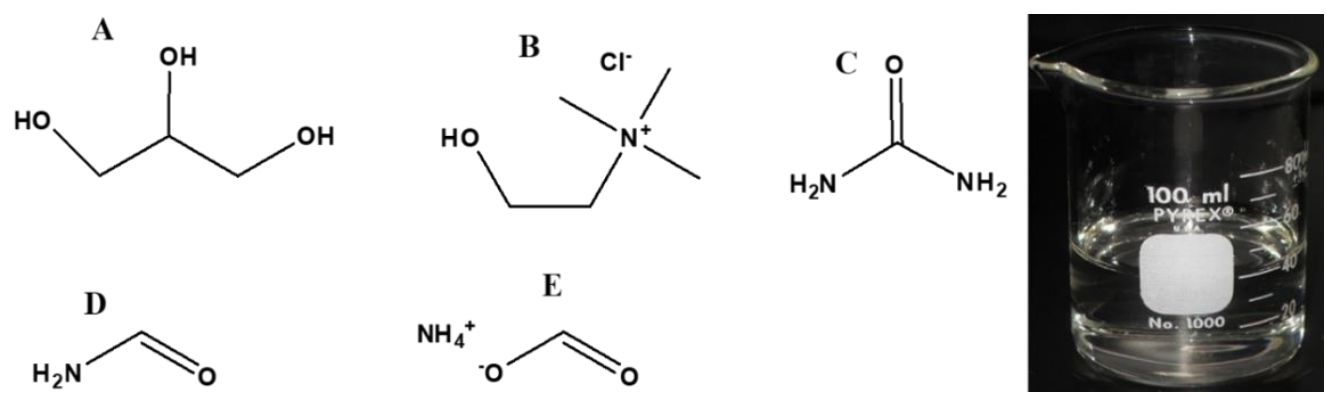

Figure 9. Key components of non-aqueous and semi-aqueous solvents are shown [113-115]: (A) glycerol, (B) choline chloride, (C) urea, (D) formamide, and (E) ammonium formate, respectively. The glass beaker shows the formation of deep eutectic solvent formed when $(\mathbf{C}, \mathbf{B})(2: 1)$ are mixed and heated with constant stirring at $80{ }^{\circ} \mathrm{C}$.

These potentially prebiotically-relevant solvents include several that could form on the early Earth and that have prebiotically plausible components. Formamide has been considered to be potentially prebiotic and has shown tremendous potential for phosphorylation reactions (see caveat regarding pure formamide $[125,133])$. In experiments with both deep eutectic solvents employed for prebiotic synthesis of glycerol phosphates $[113,114]$ and the semi-aqueous eutectic solvents [115], the yields of the glycerol phosphates were higher when formamide was used as a solvent along with silicates as catalysts [113]. The 
DESs are more stable to water as C-N bond hydrolysis is minimal, but it may be harder to justify pools arising of these two components [125,133-136].

The semi-aqueous UAFW was also efficient at phosphorylation and showed glycerol phosphate formation. Such a solvent may be more prebiotically relevant, as it is the endpoint of HCN hydrolysis under wet-dry conditions [133]. Figure 10 compares the glycerol phosphorylation in various non-aqueous (and semi-aqueous solvents).

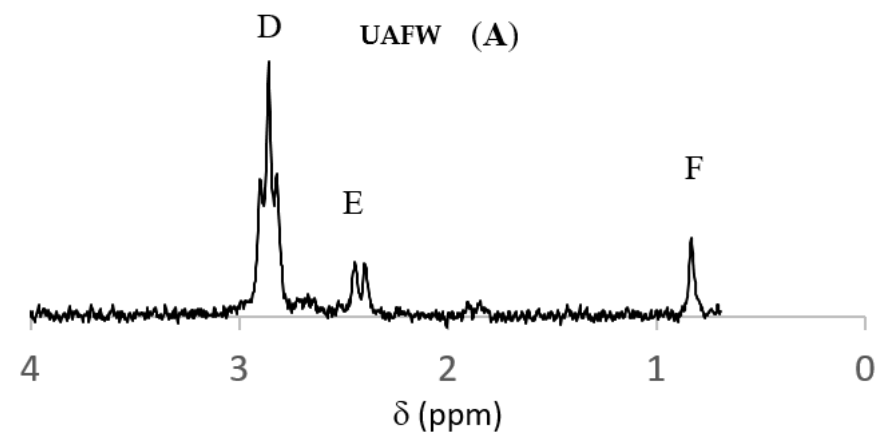

Choline chloride and glycerol DES

(B)
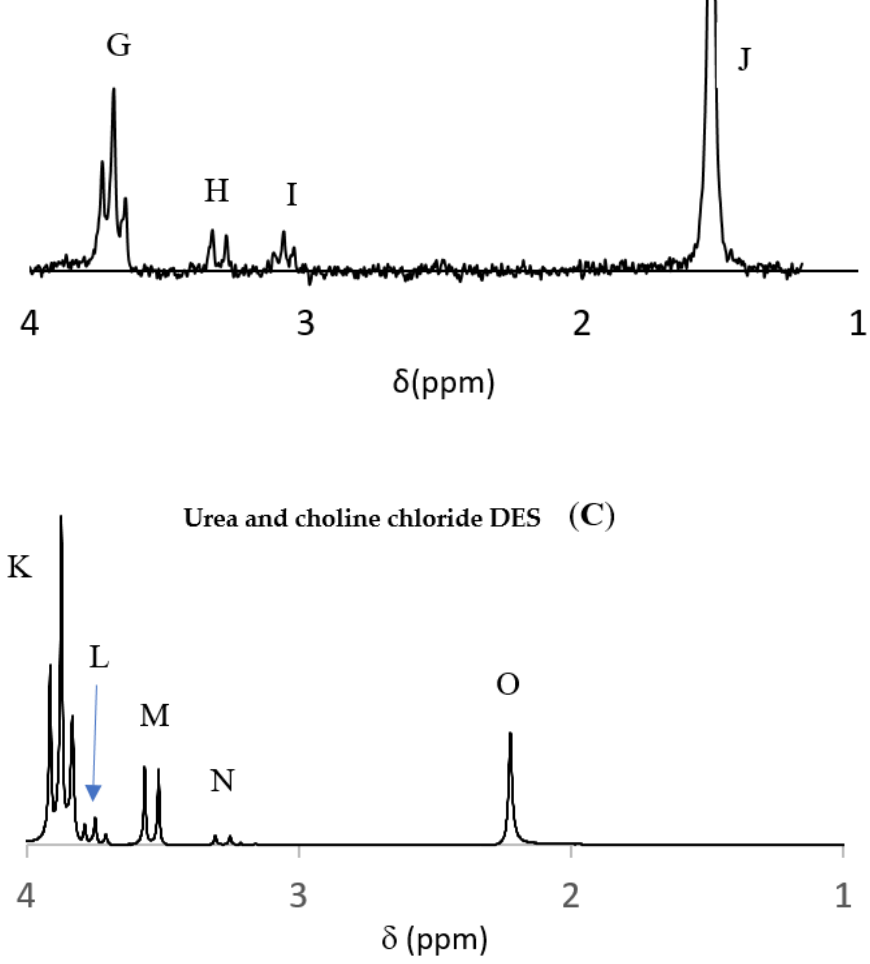

Figure 10. ${ }^{31} \mathrm{P}-\mathrm{NMR}$ spectra of glycerol phosphorylation reactions carried out in various non-aqueous solvents: (A) UAFW, (B) choline chloride and glycerol DES, (C) urea and choline chloride DES. The slight shift in the PPM value of the triplet is attributed to the $\mathrm{pH}$ changes present in the various solvents. (C) was reprinted and reused with permission from [137]; Copyright ( 2017 Elsevier.

Figure 10A shows glycerol phosphorylation reactions in the UAFW solvent; glycerol phosphorylation at the terminal position, i.e., a $\mathrm{CH}_{2}-\mathrm{O}-\mathrm{P}$ bond (shown as peak $\mathrm{D}$ ), the doublet (E) shows $\mathrm{CH}-\mathrm{O}-\mathrm{P}$ bond implying phosphorylation to form glycerol-2-phosphate, and the singlet peak (F) is orthophosphate while Figure 10B shows the phosphorylation of glycerol in a DES consisting of choline chloride and glycerol; Triplet peak (G) represents glycerol phosphorylation at the terminal position $\left(\mathrm{CH}_{2}-\mathrm{O}-\mathrm{P}\right)$, and the doublet 
$(\mathrm{H})$ is glycerol-2-phosphate. The triplet (I) is phosphocholine and the singlet peak $(\mathrm{J})$ is orthophosphate.

Finally, Figure 10C shows glycerol phosphorylation reactions in the choline chloride and urea DES. The triplet $(\mathrm{K})$ shows glycerol phosphorylation at the terminal position, the doublet $(M)$ is glycerol-2-phosphate, and the triplet $(\mathrm{L})$ and doublet $(\mathrm{N})$ represent glycerol1,2-diphosphate, and finally singlet peak O represents orthophosphate. Deep eutectic solvents-including both choline chloride: urea as well as choline chloride: glycerolperform two functions. First, they act as anhydrous medium that promotes condensation and enable dissolution of the phosphate source. Secondly, they also participate in the reaction [113]. By adding phosphate to the eutectic solvent mixture of choline chloride and urea and heating at $70-75^{\circ} \mathrm{C}$, the phosphate ester of choline (with yield around $99 \%$ based on ${ }^{31} \mathrm{P}-\mathrm{NMR}$ ) was formed. However, when glycerol was added as an additional reagent to this DES, higher yields of glycerol phosphates were obtained along with noticeable yields of phosphocholine [114]. In a similar way, a DES of choline chloride and glycerol worked efficiently by adding inorganic orthophosphate and heating at $70{ }^{\circ} \mathrm{C}$ [113].

The reactions generally involved no further reagents and employed prebiotically relevant components, though one could argue about the prebiotic relevance of the solvents. The heating of glycerol in these reactions produced $\mathrm{CH}_{2}-\mathrm{O}-\mathrm{P}$ type compounds with phosphate at the terminal C-1 position of glycerol (seen as a triplet), and, to a lesser extent, also formed a CH-O-P bond consistent with glycerol-2-phosphate. Prolonged heating (60-70 ${ }^{\circ} \mathrm{C}$ for more than $3-4$ days) also favored the formation of a cyclic glycerol phosphate species. Glycerol diphosphate was also seen as a minor product (Figure 10). An important note is that the ${ }^{31} \mathrm{P}-\mathrm{NMR}$ yields of the organophosphates and the inorganic phosphate were calculated on the basis of the total phosphorus dissolved and by the peak integration method, along with semiquantitative concentration estimation by using signal to noise ratios [135-137].

\section{Extraterrestrial Sources of Glycerol Phosphates}

Phosphorus geochemistry on the primitive Earth may have been dominated by orthophosphate minerals, primarily the calcium phosphate minerals of the apatite group [138]. These apatite minerals are endogenous sources of phosphorus. The exogenous sources of phosphorus include the meteoritic mineral schreibersite, $(\mathrm{Fe}, \mathrm{Ni})_{3} \mathrm{P}$ [139]. This mineral is likely to have been delivered by meteorites, and could have plausibly contributed up to $10 \%$ of Earth's crustal phosphorus [139-141]. Schreibersite or its synthetic analogue $\left(\mathrm{Fe}_{3} \mathrm{P}\right)$ generates a wide variety of inorganic phosphorus species [142]. Heating glycerol with an analogue of schreibersite (Figure 11) at $65^{\circ} \mathrm{C}$ for 2-3 days in an $\mathrm{N}_{2}$ atmosphere generated glycerol phosphate with yields up to $2-5 \%$ [143]. Such a reaction occurs even in water, in contrast to the "water problem" described above.

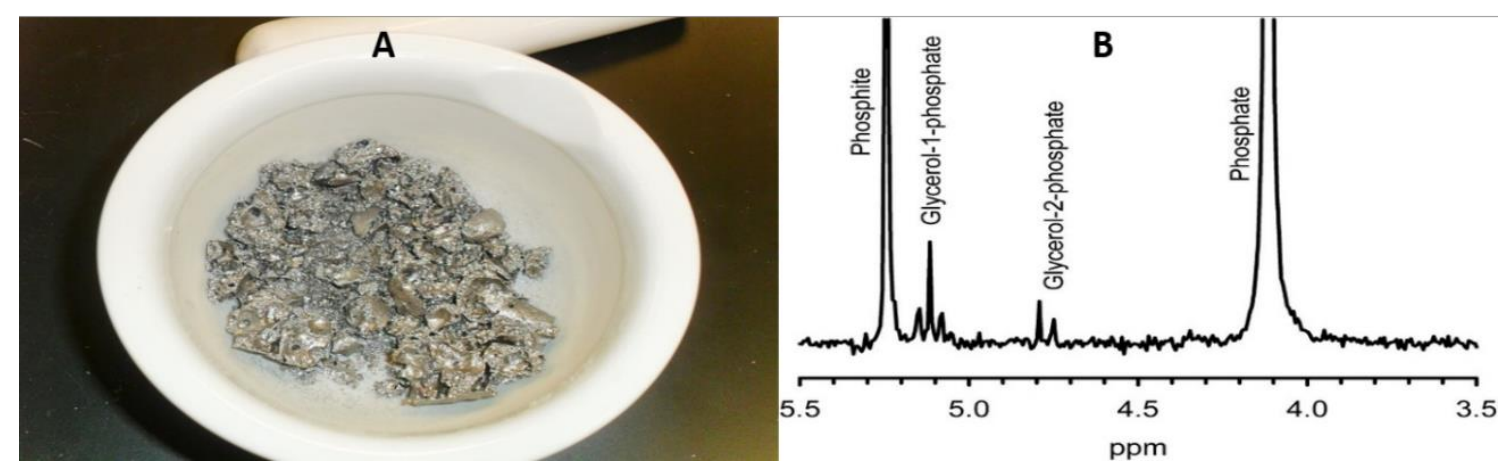

Figure 11. (A) synthesized schreibersite $\left(\mathrm{Fe}_{2} \mathrm{NiP}\right)$ [137] or its synthetic analogue $\left(\mathrm{Fe}_{3} \mathrm{P}\right)$ were used to phosphorylate glycerol under Hadean conditions in the (B) ${ }^{31} \mathrm{P}-\mathrm{NMR}$ spectrum [143]. The picture of schreibersite was reproduced and reprinted with permission from [137]; Copyright (c) 2017 Elsevier while the ${ }^{31}$ P-NMR figure shows glycerol phosphorylation by $\mathrm{Fe}_{3} \mathrm{P}$ [143]; Copyright (c) 2013 National Academy of Sciences. 


\section{Glycerol Phosphates as 'Self-Replicating' Molecules}

Aside from contributing to cellular membrane structure and other functions, glycerol phosphate has also been proposed to have possibly played a role as a 'self-replicating' molecule [144]. A system of plausible early replication involving co-polymerization of glycerate-3-phosphate and sn-glycerol-3-phosphate has been proposed that exhibits a 'covalent complementary', i.e., generates its specificity from the formation of a covalent bond, rather than an H-bond, as found in the modern nucleic acid systems [144]. This model helps in understanding the origin of self-replication and metabolic pathways.

\section{Plausible Prebiotic Syntheses of Phospholipids on the Early Earth}

It is believed that lipid-like compounds played a pivotal role in creating the necessary boundary structures capable of encapsulation of other biomolecules and hence could act as a protective boundary for early developing life [145].

Prebiotic syntheses of phospholipids such as phosphatidic acid, phosphatidyl glycerol, and phosphatidyl glycerol phosphate $(0.015 \%-0.2 \%)$ have been reported by employing chimyl alcohol, dodecanoate, glycerol, and phosphate. The condensation reactions occurred at $65^{\circ} \mathrm{C}(12 \mathrm{~h})$ (Figure 12). The reported reaction was promoted by dicyanamide and silica/kaolinite [146]. In another study, a prebiotic synthesis of phosphatidic acid was reported by condensing ammonium palmitate and glycerol phosphate at $60-100{ }^{\circ} \mathrm{C}$ for $8 \mathrm{~h}$. The reaction was aided by cyanamide and imidazole as condensation agents and the products included monopalmitoyl glycerol phosphate, dipalmitoyl glycerol phosphate, and cyclic monopalmitoyl glycerol phosphate with a combined product yield of about 45\% [147]. Similarly, the successful prebiotic synthesis of phosphatidylcholine was promoted by a condensation reaction between choline chloride and $\mathrm{Na}_{2} \mathrm{HPO}_{4}$ at $80{ }^{\circ} \mathrm{C}$ with yields around 15\% [148]. Phosphatidylethanolamine, another phospholipid, was synthesized under plausible prebiotic conditions by condensing phosphatidic acid, ethanolamine, and

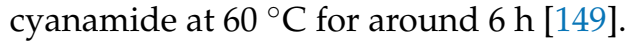

Another study also highlights a route for the prebiotic syntheses of phosphatidic acid and phosphatidylethanolamine from racemic dioleoyl glycerol [32]. This work also suggests that racemic lipids can readily form vesicles and hence also supports the idea that prebiotic amphiphilic molecules did not necessarily need to be enantioenriched for the compartmentalization of foreign biomolecules [32] (also see Section 2). The prebiotic syntheses of cyclophospholipids has been demonstrated by heating fatty acids, glycerol, imidazole, and diamidophosphate (DAP) under paste conditions (wherein the organic compounds, and DAP, with or without imidazole, were mixed and ground together with a few drops of water, then allowed to dry to a paste) [116]. The same route also synthesizes phosphates of glycerol.

It was recently demonstrated that exposing glycerol-2-phosphate to various acylating agents forms a large variety of medium-chain (C8-C10) acylglycerol-2-phosphates that readily self-assemble into vesicles. These vesicles are not only stable over varied $\mathrm{pH}$ and temperatures but also are capable of retaining mono and oligonucleotides within them. In this study, the phospholipid selectivity was also explored by subjecting the system to cycles of acylations and hydrolysis that facilitated cell membrane formation upon the accumulation of self-assembling species [150]. The reaction details (including various types of phosphorylating agents, catalysts, and other condensing agents) of many of these abovementioned reactions have been reviewed and discussed previously [108,127,136,137]. 


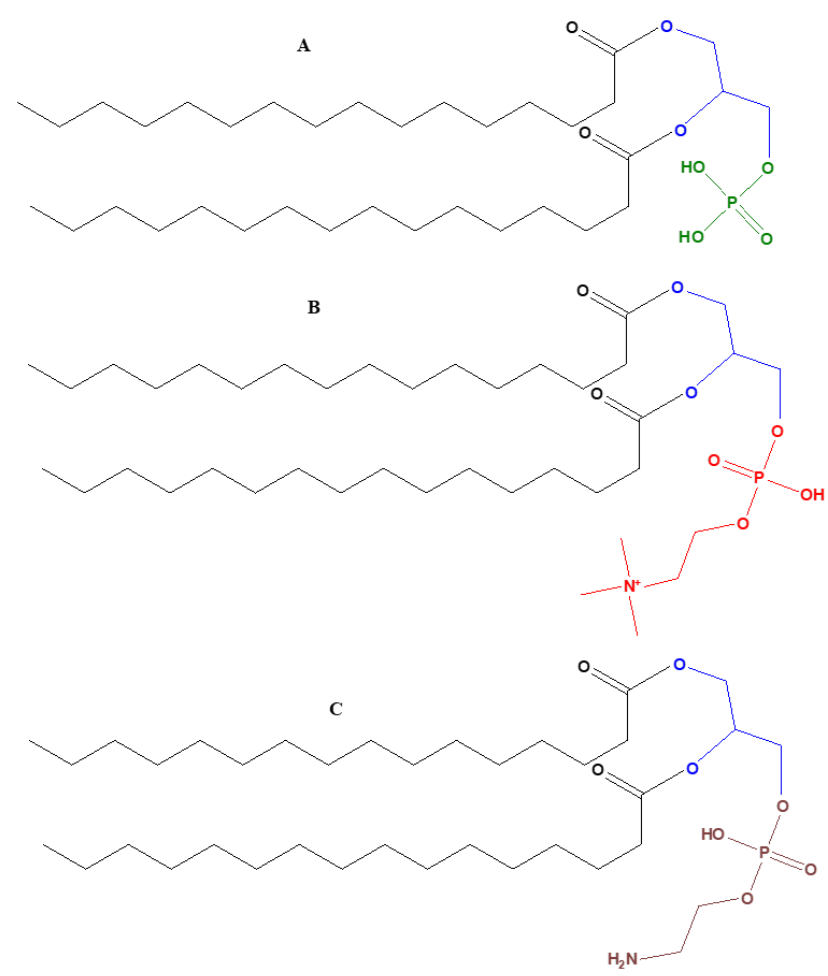

Figure 12. The generic structures of the key phospholipids: (A) phosphatidic acid with headgroup containing phosphate group (green color), (B) phosphatidylcholine with headgroup constituting of phosphocholine (red color), and (C) phosphatidylethanolamine with headgroup containing phosphoethanolamine (reddish-brown).

\section{A Few More Key Derivatives of Glycerol Relevant to Origin of Life, Biochemistry, and Modern Life}

The three compounds glyceraldehyde, DHA, and glyceric acid are the oxidation products of glycerol [151] (Figure 13). Prebiotic routes have been suggested to synthesize glyceraldehyde from simple precursors such as $\mathrm{HCN}$ and $\mathrm{H}_{2} \mathrm{~S}$ via Kiliani-Fischer type synthesis, in addition to the formose reaction. Similar routes have also been reported to form glycerol as well as glycerol phosphates [91]. Glyceraldehyde, DHA, glyceric acid, and several other polyols have also been reported to form by $\mathrm{CH}_{2} \mathrm{O}$ polymerization $[93,152]$.

An L-amino acid catalyzed route for the synthesis of excess of D-glyceraldehyde was reported in a reaction of glycolaldehyde with formaldehyde, under plausible prebiotic conditions, preferentially at acidic $\mathrm{pH}$ but also at neutral or high $\mathrm{pH}$. In this experiment, L-glyceraldehyde was preferentially formed [153]. The yield of D-glyceraldehyde was around 35\% (calculations based on by HPLC analysis). The key goal of the reported work was to focus on the enantiomeric preferences which is beyond the scope of current discussion. However, it is noteworthy here that the L-amino acid catalyzed reactions produced good yields of glyceraldehyde [153]. The reported work was a continuation of prior work focused on studying the selection of enantiomers [154]. Another study reports the use of aminonitriles for promoting the enantioselective aldol condensation of formaldehyde and glycolaldehyde to produce D-glyceraldehyde (6\%) which subsequently reacts with acetaldehyde to produce 2-deoxy-D-ribose (around 5\%). This study suggests the generation the aforementioned products via interstellar building blocks [155].

Iron (III) oxyhydroxide $(\mathrm{FeO}(\mathrm{OH}))$ has been used as a catalyst for the condensation of DL-glyceraldehyde to ketohexoses around $25{ }^{\circ} \mathrm{C}$. Under similar conditions, the isomerization and rearrangement of glyceraldehyde into dihydroxyacetone has also been reported [156]. In these reactions about $10 \%$ of the glyceraldehyde was also reported to be oxidized to glyceric acid [156]. All these reactions portray prebiotic scenarios as the catalytic iron compound can spontaneously arise from the oxidation of $\mathrm{Fe}^{2+}$ in aqueous so- 
lution. The prebiotic synthesis of phosphoglyceric acid has been reported by Kolb in which trimetaphosphate was used as a phosphorylation agent [157] and another route reports the formation of glyceraldehyde phosphate using high energy amidophosphates [158].

The above-mentioned derivatives of glycerol take part in several important biochemical reactions. One route suggests the reaction between glycolaldehyde and glyceraldehyde and provides a way to synthesize phosphoenolpyruvate [159]. In the reported synthesis phosphoenolpyruvate was derived within an $\alpha$-phosphorylation controlled reaction network that also generated other important biomolecules such as glyceric acid-2-phosphate and glyceric acid-3-phosphate. At $\mathrm{pH} 4$ the rate of phosphorylation of glyceraldehyde was observed to be $90-96 \%$. The product obtained was glyceraldehyde phosphate. Furthermore, on incubating $0.5 \mathrm{M}$ glyceraldehyde-2-phosphate, a facile dehydration to phosphoenolpyruvaldehyde (about 74\%) was reported. Incubation of glycolaldehyde-2-phosphate with formaldehyde also formed glyceraldehyde-2-phosphate (66\%). Such reactions not only highlight the mechanisms for studying the synthetic pathways of the compounds related to glycerol but also help in understanding the mechanisms of metabolic pathways (e.g., glycolysis) [159].

Recently, all three oxidation products of glycerol including glyceraldehyde, DHA, and glyceric acid were synthesized in a one-pot reaction, along with several other compounds [160]. These reactions are not prebiotically relevant and have been reported to be carried out in acetonitrile using $\mathrm{TiO}_{2}$ as a catalyst [160]. The reported reaction does imply that it might be (prebiotically) plausible to obtain glycerol's oxidation products via onepot synthetic route. The above-mentioned organic compounds and their phosphorylated derivatives (Figure 13) play significant roles in modern biochemistry and specifically in cellular respiration.

Life would not exist without these key molecules. Weber and Hsu have suggested that glyceraldehyde and glyceric acid esters could plausibly be the key molecules in the chemical evolution that led to earlier metabolic reactions $[161,162]$. Some of the characteristic features that make glyceraldehyde an ideal candidate for several metabolic pathways include its structural simplicity and plausible prebiotic synthesis from simple precursor such as formaldehyde as well as successful incorporation into various other chemical reactions to yield important biomolecules such as glycerol and energy-rich glycerol thioesters [163-165]. Glyceraldehyde-3-phosphate has been reported to form important RNA precursors. Glyceraldehyde-3-phosphate reacts with 2-amino-oxazole, cyanoacetylene, and water to produce $\alpha$-d-Cytidine- 5 '-phosphate under prebiotic conditions [166].

In another study RNA precursors such as amino-oxazolines have also been reported to be synthesized from (racemic) glyceraldehyde and 2-amino-oxazole in the presence of a chiral amino acid. The work suggests the plausible prebiotic synthesis of enantioenriched RNA precursors. Proline was reported to provide the most selective reaction and yielded about $55-58 \%$ of the amino-oxazolines [167]. The study prebiotic chemistry is a work in progress but it is all but certain that glycerol and its relevant derivatives would have played a central role in the emergence of life, the early development of biochemistry, and the formation of primitive metabolic pathways [168].<smiles>O=C(CO)CO</smiles><smiles>O=C(CO)COP(=O)(O)O</smiles><smiles>O=C(O)C(O)CO</smiles><smiles>O=C(O)C(O)COP(=O)(O)O</smiles><smiles>CC(C=O)CO</smiles>

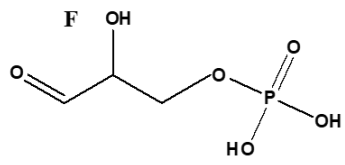

Figure 13. The various oxidation products of glycerol and their phosphorylated derivatives: (A) DHA, (B) glyceric acid, (C) glyceraldehyde, (D) DHAP, (E) phosphoglyceric acid, and (F) glyceraldehyde phosphate. 


\section{A Potential Prebiotic role for Glycerol in Nucleic Acids}

Acyclic nucleic acids have received attention recently as they introduce alternative structures to traditional DNA nanotechnology and may possibly create nanostructures that have unique chemical and physical properties that are not typically found in normal DNA structures.

From the prebiotic chemistry perspective, these plausible genetic systems can form nanostructures independent of DNA or RNA hybridization [169]. One such nucleic acid is based on glycerol (GNA). GNA's unique properties (described in detail [169]) include an ability to form both left- and right- handed helical geometries [169-171] (Figure 14). Synthetic experiments have indeed shown the 'first synthesis' of a nanostructure, generated from GNAs self-pairing that exhibit two 4-helix junctions that have mirror image symmetry [169]. The pioneering work of Ram Krishnamurthy and colleagues has also demonstrated that 'alternative genetic systems' are stable. The nucleic acid iso-GNA is an isomer of glycerol-derived nucleic acids that performs base pairing even as a simple oligonucleotide [172]. This raises a question: were 'traditional' RNA and DNA the only plausible genetic systems in early developing life? The recent development of alternative nucleic acid systems, including that of glycerol in iso-GNA phosphoramidites, has applications in medical sciences and DNA technology, far beyond the realm of prebiotic chemistry [173].

A
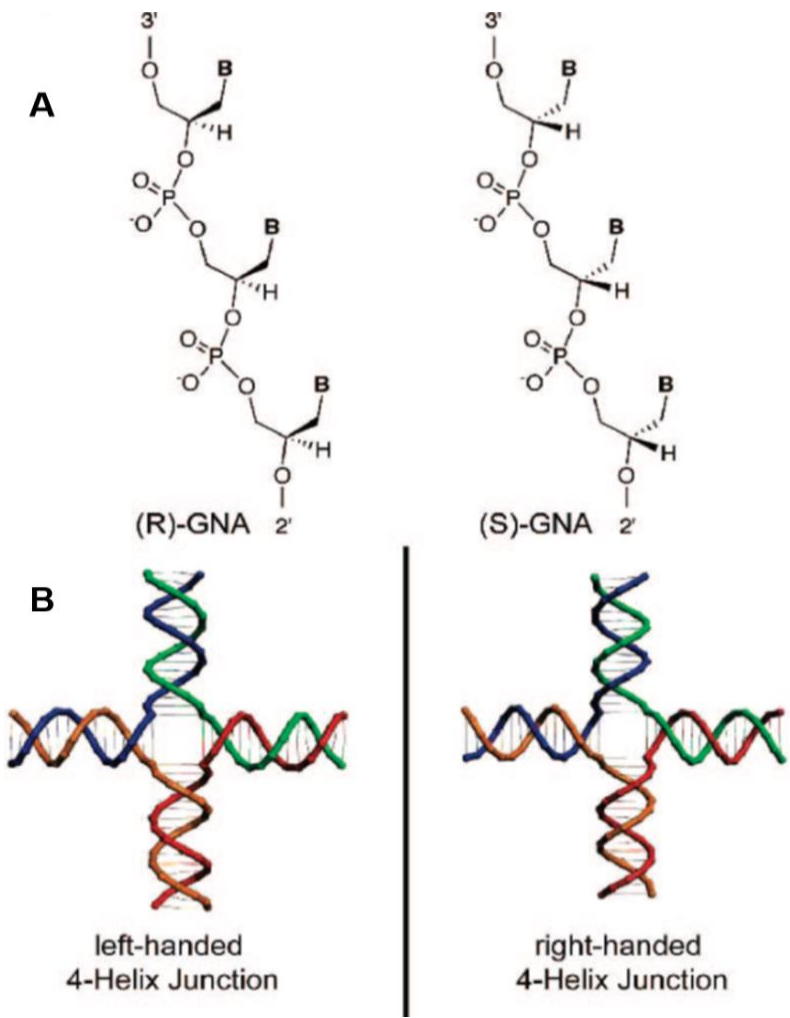

Figure 14. An immobile 4-helix junction comprising of GNA: (A) The chemical structures of (R)- and (S)-GNA, where ' $\mathrm{B}$ ' in the structure of figure A means a nucleobase and (B) left and right-handed 4helix structure of GNA. Figure reproduced with permission from [169]; Copyright $\odot$ 2008, American Chemical Society.

\section{Recapitulation and Closing Thoughts}

Glycerol and all its previously discussed derivatives should be considered significant to the origin and chemical evolution of prebiotic molecules on the early Earth. Such processes are ultimately recapitulated in modern biochemistry, though this evidence is convoluted by billions of years of evolution. Metabolic activities require these glycerol-based compounds and its derivatives as a subset of the reactions that generate new molecules or 
energy. The successful prebiotic syntheses of glycerol have been achieved by using simple precursor molecules such as $\mathrm{HCN}, \mathrm{CH}_{2} \mathrm{O}$, and $\mathrm{H}_{2} \mathrm{~S}$, and there is no reason to assume its absence in prebiotic chemistry [91]. Its presence in prebiotic chemistry is further supported by the relative ease with which it is formed from astrophysical materials [92] and by its abundance in carbonaceous chondrites [96].

Simple lipids or acylglycerols have been prepared under simulated prebiotic conditions mainly through hydrothermal routes $[104,105]$ and complex lipids and phospholipids have also been prepared under plausibly prebiotic conditions [116,146-149], as well as glycerol phosphates (Table 1). The prebiotic phosphorylation of glycerol via the meteorite mineral schreibersite [143] poses a route to the synthesis of glycerol phosphates and to other biological organophosphate molecules, especially since this reaction occurs in water due to the exergonic corrosion of schreibersite. In addition, the release of highly soluble phosphites into water and even icy environments on other planets may produce alternative glycerol phosphites.

Glycerol phosphates play a role in the evolution of membranes. This points to a key role for the molecule in the development of life. However, in archaea-in contrast to eukaryotes and bacteria-phospholipids are comprised of sn-glycerol-1-phosphate and their hydrophobic side chains contain isoprenoid units that are linked up with snglycerol-1-phosphate via ether linkages, distinguishing them from the other domains of life [34-37]. The unifying features of these membranes remain glycerol and phosphate, and this divergence demonstrates that the fatty acid component of lipids is not conserved across the domains of life. There are many hypotheses that discuss the plausibility and evolution of the modern membranes containing sn-glycerol-3-phosphate, with constraints provided by these distinctive differences as discussed previously. Ultimately these molecules fed into lipid membranes. The formation of early membranes is also an open question with routes to answers from prebiotic chemistry, geobiology, and evolutionary biology. The timing of when 'modern biochemistry' got the sn-glycerol-3-phosphate as a precursor is also unknown.

Moreover, glycerol plays a highly significant role in the lives of extremophiles such as halophiles as it is the product of a photosynthesis reaction of certain red algae (genus Dunaliella) in which $\mathrm{CO}_{2}$ is fixed in the form of glycerol [47-49]. In addition to being a pivotal part of lipids and phospholipids and performing other metabolic activities, glycerol's oxidation products such as glyceric acid, glyceraldehyde, and DHA also played a role in the origin and evolution of life. The phosphorylated derivatives of these compounds are critical parts of metabolism. The prebiotic synthesis of phosphorylated derivatives of these compounds has been demonstrated [151-164], and these compounds serve as "feedstock" molecules to more complex sugars and macromolecules. Glycerol has also been demonstrated to serve as a backbone in synthetic nucleic acids as iso-GNAs [169-173]. These roles highlight a potential for a more independent, self-replicating system relevant to the origin of information transfer and early life (Figure 15), with glycerol playing a central role, and less contingent on a comparatively difficult to synthesize ribose backbone.

A condition of prebiotic chemistry is to demonstrate a prebiotic synthesis of molecules that are not only efficient, but also that portray a 'realistic prebiotic scenario,' i.e., conditions as simplistic as possible and related to a likely environment on the early Earth. Given a role for glycerol and its derivatives in prebiotic chemistry, it is hence important to find realistic prebiotic sources of glycerol on the early Earth, and for all of its major derivatives, including phospholipids, that would have played a significant role in the origin and evolution of life on the early Earth. Furthermore, there are issues that prebiotic chemistry still suffers with such as the problem of water as a solvent for condensation reactions, the plausibility of condensation agents on the early Earth, and the fact that mineral catalysts are generally ineffective at producing biomolecules at high yields. Some solutions offered by prebiotic chemistry - such as the use of the so-called aqueous solvents including formamide, UAFW, and DESs-remain difficult to justify as the potential presence on the early Earth in large quantities is unlikely. 


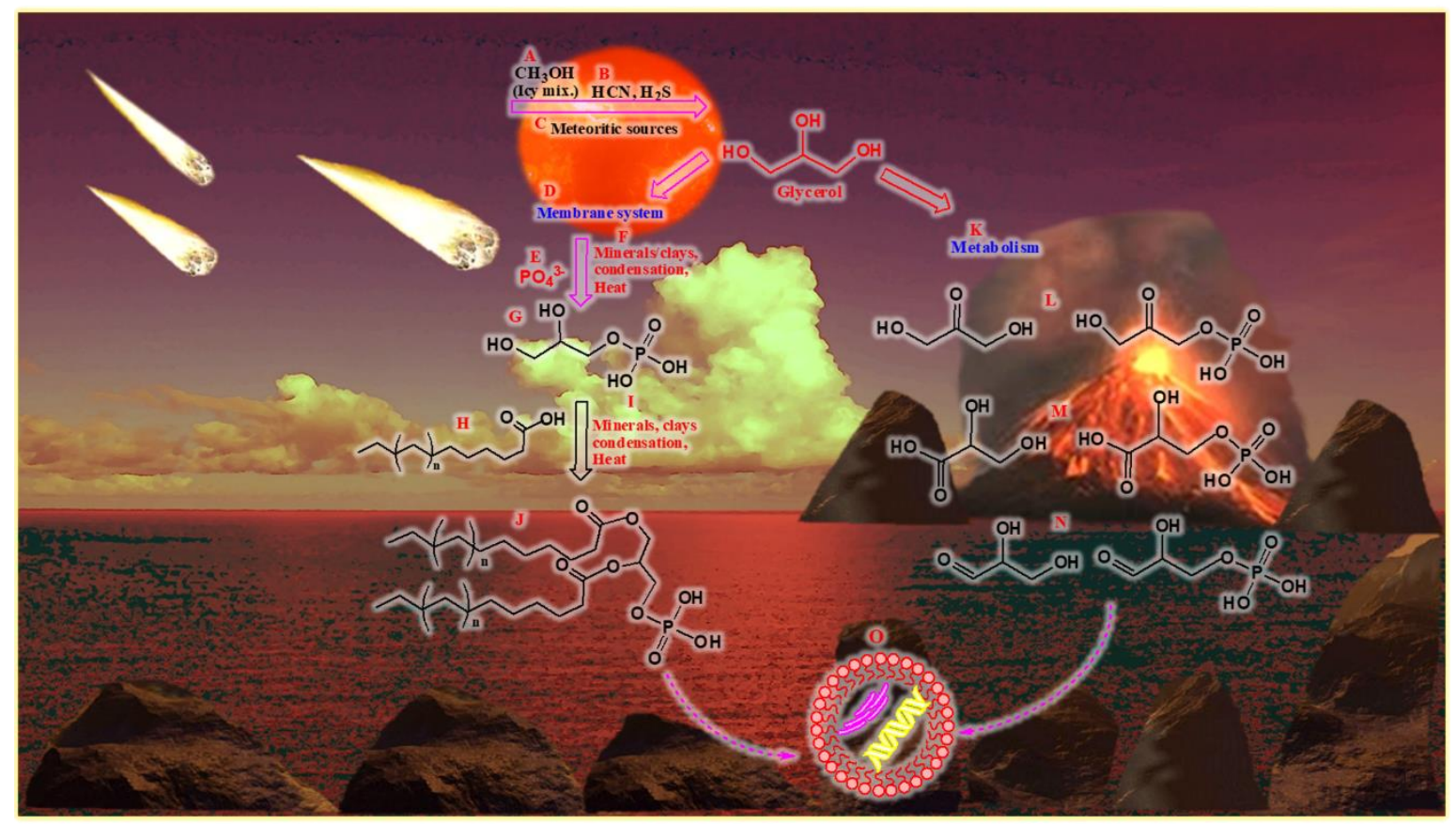

Figure 15. A schematic description of the plausible role played by glycerol during prebiotic synthesis and chemical evolution: (A,B) the prebiotic synthesis and origin of glycerol, (C) glycerol detection in meteorites, (D) the pathway by which glycerol is involved in the origin and development of cell membranes, (E) various phosphate sources employed in the phosphorylation reactions, (F) various minerals/clays employed in the phosphorylation, (G) formation of glycerol phosphates, (H) condensation reactions of glycerol phosphates with fatty acids, (I) specific minerals/clays used for the condensation reaction between glycerol phosphates and fatty acids, (J) formation of phospholipids, and (K) role of glycerol and its derivatives in various metabolic pathways The key derivatives include: (L) DHA and DHAP, (M) glyceric acid and phosphoglyceric acid, (N) glyceraldehyde and glyceraldehyde phosphate, respectively, and finally (O), an early developing cell on the early Earth, containing the metabolic molecules encapsulated by lipids/early cell membranes.

Darwin first discussed a warm pond model in prebiotic chemistry [125]. If water is removed from such environment while the organic and phosphate remain intact, phosphorylation could readily occur, especially if anhydrous solvents such as formamide remain. However, pure formamide pools are unlikely to have existed on the early Earth because of the former compound's formation by the reaction of formamide results in its hydrolysis to ammonium formate. Other examples of anhydrous solvents include eutectic mixture of urea: choline chloride, glycerol: choline chloride $[113,114]$ but plausibility of such solvents is questionable as suggested by both Pasek and Schwatrz [125,133,134]. Recently, mixtures of urea, ammonium formate, and water present another plausible solvent for prebiotic reactions but, as mentioned earlier, the abundance of such substances on the early Earth is also questionable. Besides these routes, a few other experiments do produce glycerol or its relevant derivatives in higher yields, but these utilize compounds whose presence on the early Earth could also be questionable [150,159] (e.g., chlorite/DMSO used in [159]). The above-mentioned issues remain as open questions in the realm of prebiotic chemistry.

One plausible hypothesis could be the abiotic syntheses of glycerol and other associated compounds under plausible astrophysical environments such as very low temperatures (typically, $<20 \mathrm{~K}$ ) and very low pressures (typically, $<10^{-8} \mathrm{mbar}$ ), and high doses of ionizing radiation (UV or X-rays, or high-energy electrons, or high-energy protons). It is possible that glycerol, along with other organic compounds synthesized extra-terrestrially, would have been subsequently delivered to the early Earth and potentially mixed into hot pools of water. Drying hydrothermal sites could have kickstarted the process of prebiotic condensation of lipids and ultimately of membrane like structures. This is also supported by the fact that a large number of organic molecules that are used in modern biochemistry are found in the interstellar medium, comets, asteroids, meteorites, and interplanetary 
dust particles. It is plausible that large quantities of extraterrestrial organic compounds were delivered to the early Earth via meteorites to plausibly initiate the process of prebiotic syntheses [172-181].

Furthermore, researchers have directly linked the significance of meteorites, their impacts, and the origin of life on the early Earth [182,183]. According to this theory, organic compounds could plausibly have been generated by shock processing of the atmosphere [184,185] or during the impact [186], and which could later get rained into nearby hydrothermal systems. The theory suggests the origin/formation of zeolites and clays in the impact hydrothermal systems as one of the most significant links between impact craters and the origin of life. Such clays and zeolites are significant for the origin of life as these are believed to have provided assistance with the prebiotic syntheses of biomolecules and their subsequent concentration (as well as polymerization) on the early Earth [187-197]. Furthermore, impact craters could also plausibly have provided a suitable niche for the proliferation of the early life on the Earth. Rock fractured during impacts could possibly increase the surface area available for the colonization of an incipient ecosystem [198,199]. Hence, there is a strong possibility of the emergence of life on the early Earth as a consequence of the abiotic synthesis of organic molecules via interstellar chemical reactions and their subsequent delivery to early Earth via meteoritic bombardments, followed by concentration, self-assembly reactions catalyzed by the minerals present on the early Earth, and finally the proliferation of the early life on the Earth.

Author Contributions: M.G. designed the conceptualization and main idea, prepared figures and tables, and wrote the review article. M.A.P. designed and wrote the review article. All authors have read and agreed to the published version of the manuscript.

Funding: This work was supported by NASA Exobiology program (80NSSCC18K1288).

Institutional Review Board Statement: Not applicable.

Informed Consent Statement: Not applicable.

Data Availability Statement: Not applicable.

Acknowledgments: This work has been supported in part by University of South Florida Interdisciplinary NMR Facility, The Department of Chemistry and the College of Arts and Sciences, Tampa, Florida. The mass spectrometry data analysis has been supported by the Chemical Purification Analysis and Screening Core Facility (CPAS) at University of South Florida. Authors thank Edwin Rivera from USF-NMR facility for the help with NMR and Laurent Calcul for mass spectrometric analysis, Tian Feng for help with the manuscript, and Chris Hunkeler for providing permission to use the red algae of lake Chaxa. The original link of his images can be found at: https:/ / www.flickr.com/photos/chrishunkeler/39934221843/in/photostream/. Thanks are also due to Andrew O. Stella Vega for his suggestions to improve the paper. Maheen Gull is extremely thankful to Ryan Barkley for the help with the graphics and support during the manuscript preparation and finally to her parents and her daughters Luna and Nova Barkley for inspiration and motivation.

Conflicts of Interest: The authors declare no conflict of interest.

\section{Glossary of terms}

Aminonitrile

An organic compound that contains both an amino and a nitrile functional group. Relevant compounds such as $\alpha$-amino nitriles are important intermediates in Strecker type synthesis of amino acids.

Cenancestor The most recent ancestor (organism) from which living beings have evolved.

Chiral molecules Tetrahedral organic centers (usually carbon) that have different arrangements of functional groups, resulting in 3D differences in structure. A type of high-energy condensed phosphate that has been known to

Diamidophosphate efficiently phosphorylate organics such as sugars, alcohols, and other compounds.

Enantiomers Chiral molecules that are mirror image of each other. 
Eukaryotes and
prokaryotes

GDPH

Heterotrophic
bacteria
Isomers
Kiliani-Fischer
type synthesis

Light and Dark reactions

Lipolysis

Mafic and ultramafic rocks

Strecker type synthesis Racemic mixture

Symbiosis

The Embden-

Meyerhof-Parnas pathway
Eukaryotes are organisms in which nucleus and genetic material is confined within the boundaries of a nuclear membrane whereas prokaryotes do not have a well-defined definite nuclear membrane. Also known as 'Glycerol phosphate dehydrogenase', this is an enzyme that catalyzes the reversible conversion of dihydroxyacetone phosphate to sn-glycerol-3-phosphate. This process involves a redox process. $\mathrm{G}_{1} \mathrm{DPH}$ catalyzes the glycerol-1-phosphate formation in primitive organisms such as archaea while $\mathrm{G}_{3} \mathrm{DPH}$ catalyzes the formation of glycerol-3-phosphate in modern organisms and in many bacteria.

Bacteria that cannot photosynthesize.

Organic compounds having same molecular but different structural formulas.

A method of synthesizing monosaccharides. Cyanide (e.g., $\mathrm{NaCN}$ ) is added via nucleophilic addition to the carbonyl group of a sugar, resulting in an increase in carbon number of the sugar.

The first stage of photosynthesis is to trap light energy and to form ATP and NADPH from light (commonly referred as 'light reactions'). The second stage synthesizes glucose by $\mathrm{CO}_{2}$ fixation and utilizing stored chemical energy is called the 'dark reaction'.

The hydrolytic cleavage of ester bonds in the triglycerides to generate fatty acids and glycerol.

These are $\mathrm{SiO}_{2}$-poor igneous rocks: Mafic rocks are dominated with plagioclase and pyroxene and ultramafic rocks are rich in olivine and pyroxene.

An organic chemical reaction that produces amino acids by the reaction of an aldehyde with ammonium chloride and cyanide.

A mixture containing equal amounts of right and left-handed molecules. A long-term association between two living organisms which could either be beneficial or harmful, i.e., mutualism (association benefits both) or parasitism (one benefits, other is harmed).

The biochemical pathway that allows the consumption of glucose to generate ATP, NADH, and many other biosynthetic precursors, e.g., 3-phosphoglycerate or pyruvate.

\section{References}

1. Robergs, R.A.; Griffin, S.E. Glycerol Biochemistry, Pharmacokinetics and Clinical and Practical Applications. Sports Med. 1998, 26, 145-167. [CrossRef] [PubMed]

2. Mugabo, Y.; Zhao, S.; Seifried, A.; Gezzar, S.; Al-Mass, A.; Zhang, D.; Lamontagne, J.; Attane, C.; Poursharifi, P.; Iglesias, J.; et al. Identification of a mammalian glycerol-3-phosphate phosphatase: Role in metabolism and signaling in pancreatic $\beta$-cells and hepatocytes. Proc. Natl. Acad. Sci. USA 2016, 113, E430-E439. [CrossRef] [PubMed]

3. Elia, M.; Khan, K.; Calder, G.; Kurpad, A. Glycerol exchange across the human forearm assessed by a Combination of tracer and arteriovenous exchange techniques. Clin. Sci. 1993, 84, 99-104. [CrossRef] [PubMed]

4. Bortz, W.M.; Paul, P.; Haff, A.C.; Holmes, W.L. Glycerol turnover and oxidation in man. J. Clin. Investig. 1972, 51, 1537-1546. [CrossRef]

5. Newsholme, E.A.; Taylor, K. Glycerol kinase activities from vertebrates and invertebrates. Biochem. J. 1969, 112, 465-474. [CrossRef]

6. Frank, M.S.B.; Nahata, M.C.; Hilty, M.D. Glycerol: A review of its pharmacology, pharmacokinetics, adverse reactions, and clinical use. Pharmacotherapy 1981, 1, 147-160. [CrossRef]

7. Lin, E.C. Glycerol utilization and its regulation in mammals. Annu. Rev. Biochem. 1977, 46, 765-795. [CrossRef]

8. Oscai, L.B.; Essig, D.A.; Palmer, W.K. Lipase regulation of muscle triglyceride hydrolysis. J. Appl. Physiol. 1990, 69, 1571-1577. [CrossRef]

9. Saponaro, C.; Gaggini, M.; Carli, F.; Gastaldelli, A. The Subtle Balance between Lipolysis and Lipogenesis: A Critical Point in Metabolic Homeostasis. Nutrients 2015, 7, 9453-9474. [CrossRef]

10. Rotondo, F.; Ho-Palma, A.C.; Remesar, X.; Fernández-López, J.A.; Romero, M.D.M.; Alemany, M. Glycerol is synthesized and secreted by adipocytes to dispose of excess glucose, via glycerogenesis and increased acyl-glycerol turnover. Sci. Rep. 2017, 7, 8983. [CrossRef]

11. Jansson, P.A.; Larsson, A.; Smith, U.; Lönnroth, P. Glycerol production in subcutaneous adipose tissue of lean and obese humans. J. Clin. Investig. 1992, 89, 1610-1617. [CrossRef] [PubMed] 
12. Langin, D. Control of fatty acid and glycerol release in adipose tissue lipolysis. Comptes Rendus Biol. 2006, 329, 598-607. [CrossRef] [PubMed]

13. Chakrabarty, K.; Bombeck, C.T.; Sigel, B.; Tauber, J.W.; Jeffay, H. Glycerokinase activity in human adipose-tissue as related to obesity. Int. J. Obesity 1984, 8, 609-622.

14. Ross, B.D.; Hems, R.; Krebs, H.A. The rate of gluconeogenesis from various precursors in the perfused rat liver. Biochem. J. 1967, 102, 942-951. [CrossRef]

15. Roca, P.; Sáinz, F.; González, M.; Alemany, M. Energetic components in the unincubated egg fractions of several avian species. Comp. Biochem. Physiol. B 1982, 72, 439-443. [CrossRef]

16. Saito, H.; Posas, F. Response to hyperosmotic stress. Genetics 2012, 192, 289-318. [CrossRef]

17. Engelking, L.R. Gluconeogenesis. In Textbook of Veterinary Physiological Chemistry, 3rd ed.; Academic Press: Cambridge, MA, USA, 2015; pp. 225-230.

18. Driedzic, W.R.; Short, C.E. Relationship between food availability, glycerol and glycogen levels in low-temperature challenged rainbow smelt Osmerus mordax. J. Exp. Biol. 2007, 210, 2866-2872. [CrossRef]

19. Ewart, K.V.; Fletcher, G.L. Isolation and characterization of antifreeze proteins from smelt (Osmerus mordax) and Atlantic herring (Clupea harengus harengus). Can. J. Zool. 1990, 68, 1652-1658. [CrossRef]

20. Raymond, J.A. Glycerol is a colligative antifreeze in some northern fishes. J. Exp. Zool. 1992, 262, 347-352. [CrossRef]

21. Klein, M.; Swinnen, S.; Thevelein, J.M.; Nevoigt, E. Glycerol metabolism and transport in yeast and fungi: Established knowledge and ambiguities. Environ. Microbiol. 2017, 19, 878-893. [CrossRef]

22. Cray, J.A.; Stevenson, A.; Ball, P.; Bankar, S.B.; Eleutherio, E.C.; Ezeji, T.C.; Singhal, R.S.; Thevelein, J.M.; Timson, D.J.; Hallsworth, J.E. Chaotropicity: A key factor in product tolerance of biofuel-producing microorganisms. Curr. Opin. Biotechnol. 2015, 33, 228-259. [CrossRef] [PubMed]

23. Xiberras, J.; Klein, M.; Nevoigt, E. Glycerol as a substrate for Saccharomyces cerevisiae based bioprocesses-Knowledge gaps regarding the central carbon catabolism of this 'non-fermentable' carbon source. Biotechnol. Adv. 2019, 37, 107378. [CrossRef] [PubMed]

24. Nevoigt, E.; Stahl, U. Osmoregulation and glycerol metabolism in the yeast Saccharomyces cerevisiae. FEMS Microbiol. Rev. 1997, 21, 231-241. [CrossRef] [PubMed]

25. Blomberg, A. Metabolic surprises in Saccharomyces cerevisiae during adaptation to saline conditions: Questions, some answers and a model. FEMS Microbiol. Lett. 2000, 182,1-8. [CrossRef]

26. Chen, X.; Fang, H.; Rao, Z.; Shen, W.; Zhuge, B.; Wang, Z.; Zhuge, J. Cloning and characterization of a NAD ${ }^{+}$-dependent glycerol-3-phosphate dehydrogenase gene from Candida glycerinogenes, an industrial glycerol producer. FEMS Yeast Res. 2008, 8, 725-734. [CrossRef]

27. Cedric, B.; Jörg, S. Glycerol metabolism and its implication in virulence in Mycoplasma. FEMS Microbiol. Rev. 2017, 41, 640-652.

28. Córdova, A.; Notz, W.; Barbas, C.F., 3rd. Direct organocatalytic aldol reactions in buffered aqueous media. Chem. Commun. 2002, 24, 3024-3025.

29. Clough, S.R. Glyceraldehyde. In Encyclopedia of Toxicology, 2nd ed.; Elsevier: Amsterdam, The Netherlands, 2005 ; pp. $448-449$.

30. Björkman, O. Comparative studies on photosynthesis in higher plants. In Photophysiology Current Topics in Photobiology and Photochemistry; Giese, A.C., Ed.; Academic Press: Cambridge, MA, USA, 1973; Volume 8, pp. 1-63.

31. Chozhavendhan, S.; Devi, G.K.; Bharathiraja, B.; Kumar, R.P.; Elavazhagan, S. Assessment of crude glycerol utilization for sustainable development of biorefineries. In Refining Biomass Residues for Sustainable Energy and Bioproducts. Technology, Advances, Life Cycle Assessment, and Economics; Kumar, R.P., Gnansounou, E., Raman, J.K., Baskar, J., Eds.; Academic Press: Cambridge, MA, USA, 2020; pp. 195-212.

32. Fayolle, D.; Altamura, E.; D’Onofrio, A.; Madanamothoo, W.; Fenet, B.; Mavelli, F.; Buchet, R.; Stano, P.; Fiore, M.; Strazewski, P. Crude phosphorylation mixtures containing racemic lipid amphiphiles self-assemble to give stable primitive compartments. Sci. Rep. 2017, 7, 18106. [CrossRef]

33. Weis, R.M.; McCollen, H.M. Two-dimensional chiral crystals of phospholipids. Nature 1984, 310, 47-49. [CrossRef]

34. Lombard, J.; López-García, P.; Moreira, D. The early evolution of lipid membranes and the three domains of life. Nat. Rev. 2012, 10, 507-515. [CrossRef]

35. Peretó, J.; López-García, P.; Moreira, D. Ancestral lipid biosynthesis and early membrane evolution. Trends Biochem. Sci. 2004, 29, 469-477. [CrossRef] [PubMed]

36. Kates, M. The phytanyl ether-linked polar lipids and isoprenoid neutral lipids of extremely halophilic bacteria. Prog. Chem. Fats Other Lipds 1977, 15, 301-342. [CrossRef]

37. Kate, M. Membrane lipids of archaea. In New Comprehensive Biochemistry; Kates, M., Kushner, D.J., Matheson, A.T., Eds.; Elsevier: Amsterdam, The Netherlands, 1993; Volume 26, pp. 261-295.

38. Koga, Y. Thermal Adaptation of the Archaeal and Bacterial Lipid Membranes. Archaea 2012, 2012, 789652. [CrossRef] [PubMed]

39. Jain, S.; Caforio, A.; Driessen, A.J. Biosynthesis of archaeal membrane ether lipids. Front. Microbiol. 2014, 5, 1-16. [CrossRef] [PubMed]

40. Koga, Y.; Kyuragi, T.; Nishihara, M. Did archaeal and bacterial cells arise independently from noncellular precursors? A hypothesis stating that the advent of membrane phospholipid with enantiomeric glycero-phosphate backbones caused the separation of the two lines of descent. J. Mol. Evol. 1998, 46, 54-63. [CrossRef] [PubMed] 
41. Martin, W.; Russell, M.J. On the origins of cells: A hypothesis for the evolutionary transitions from abiotic geochemistry to chemoautotrophic prokaryotes, and from prokaryotes to nucleated cells. Philos. Trans. R. Soc. Lond. Ser. B 2003, 358, 59-83. [CrossRef] [PubMed]

42. Wächtershäuser, G. From pre-cells to eukarya-A tale of two lipids. Mol. Microbiol. 2003, 47, 13-22. [CrossRef]

43. Fiore, M.; Buchet, R. Symmetry Breaking of Phospholipids. Symmetry 2020, 12, 1488. [CrossRef]

44. Rampelotto, P.H. Extremophiles and Extreme Environments. Life 2013, 3, 482-485. [CrossRef]

45. Merino, N.; Aronson, H.S.; Bojanova, D.P.; Feyhl-Buska, J.; Wong, M.L.; Zhang, S.; Giovannelli, D. Living at the Extremes: Extremophiles and the Limits of Life in a Planetary Context. Front. Microbiol. 2019, 10, 780.

46. Javaux, E.J. Extreme life on Earth-Past, present and possibly beyond. Res. Microbiol. 2006, 157, 37-48. [CrossRef] [PubMed]

47. Oren, A. Glycerol metabolism in hypersaline environments. Environ. Microbiol. 2017, 19, 851-863. [CrossRef] [PubMed]

48. Craigie, J.S.; McLachlan, J. Glycerol as a photosynthetic product in Dunaliella tertiolecta Butcher. Can. J. Bot. 1964, 42, 777-778. [CrossRef]

49. Ben-Amotz, A.; Avron, M. The Role of Glycerol in the Osmotic Regulation of the Halophilic Alga Dunaliella parva. Plant Physiol. 1973, 51, 875-878. [CrossRef]

50. Ben-Amotz, A. Adaptation of the unicellular alga Dunaliella parva to a saline environment. J. Phycol. 1975, 11, 50-54. [CrossRef]

51. Borowitzka, L.J.; Brown, A.D. The salt relations of marine and halophilic species of the unicellular green alga, Dunaliella. The role of glycerol as a compatible solute. Arch. Microbiol. 1974, 96, 37-52. [CrossRef]

52. Borowitzka, L.J.; Kessly, D.S.; Brown, A.D. The salt relations of Dunaliella. Further observations on glycerol production and its regulation. Arch Microbiol. 1977, 113, 131-138. [CrossRef]

53. Brown, A.D. Microbial water stress. Bacteriol. Rev. 1976, 40, 803-846. [CrossRef] [PubMed]

54. Ben-Amotz, A.; Avron, M. NADP specific dihydroxyacetone reductase from Dunaliella parva. FEBS Lett. 1973, $29,153-155$. [CrossRef]

55. Ben-Amotz, A.; Sussman, I.; Avron, M. Glycerol production by Dunaliella. In New Trends in Research and Utilization of Solar Energy through Biological Systems; Mislin, H., Bachofen, R., Eds.; Springer: Basel, Switzerland, 1982; Volume 38, pp. 49-52.

56. Goyal, A. Osmoregulation in Dunaliella, Part II: Photosynthesis and starch contribute carbon for glycerol synthesis during a salt stress in Dunaliella tertiolecta. Plant Physiol. Biochem. 2007, 45, 705-710. [CrossRef] [PubMed]

57. Da Costa, M.S.; Rainey, F.A.; Nobre, M.F. The Prokaryotes. In The Genus Thermus and Relatives; Dworkin, M., Falkow, S., Rosenberg, E., Schleifer, K.H., Stackebrandt, E., Eds.; Springer: New York, NY, USA, 2006; Volume 7, pp. 797-812.

58. Falb, M.; Müller, K.; Königsmaier, L.; Oberwinkler, T.; Horn, P.; von Gronau, S.; Gonzalez, O.; Pfeiffer, F.; Bornberg-Bauer, E.; Oesterhelt, D. Metabolism of halophilic archaea. Extremophiles 2008, 12, 177-196. [CrossRef] [PubMed]

59. Rawal, N.; Kelkar, S.M.; Altekar, W. Alternative routes of carbohydrate metabolism in halophilic archaebacteria. Indian J. Biochem. Biophys. 1988, 25, 674-686. [PubMed]

60. Patil, Y.; Junghare, M.; Muller, N. Fermentation of glycerol by Anaerobium acetethylicum and its potential use in biofuel production. Microb. Biotechnol. 2017, 10, 203-217. [CrossRef] [PubMed]

61. Patil, Y.; Junghare, M.; Pester, M.; Müller, N.; Schink, B. Characterization and phylogeny of Anaerobium acetethylicum gen. nov., sp. nov., a strictly anaerobic gluconate-fermenting bacterium isolated from a methanogenic bioreactor. Int. J. Syst. Evol. Microbiol. 2015, 65, 3289-3296. [CrossRef]

62. Hidalgo, M.; Puerta-Fernández, E. Fermentation of glycerol by a newly discovered anaerobic bacterium: Adding value to biodiesel production. Microb. Biotechnol. 2017, 10, 528-530. [CrossRef]

63. Stevenson, A.; Cray, J.A.; Williams, J.P.; Santos, R.; Sahay, R.; Neuenkirchen, N.; McClure, C.D.; Grant, I.R.; Houghton, J.D.; Quinn, J.P.; et al. Is there a common water-activity limit for the three domains of life? ISME J. 2015, 9, 1333-1351. [CrossRef]

64. Stevenson, A.; Hamill, P.G.; Medina, Á.; Kminek, G.; Rummel, J.D.; Dijksterhuis, J.; Timson, D.J.; Magan, N.; Leong, S.L.; Hallsworth, J.E. Glycerol enhances fungal germination at the water-activity limit for life. Environ. Microbiol. $2017,19,947-967$. [CrossRef]

65. Norkrans, B.; Kylin, A. Regulation of the potassium to sodium ratio and of the osmotic potential in relation to salt tolerance in yeasts. J. Bacteriol. 1969, 100, 836-845. [CrossRef]

66. Pasteur, M.L. Production constante de glycérine dans la fermentation alcoolique. C. R. Acad. Sci. 1858, 46, 857. (In French)

67. Semkiv, M.V.; Ruchala, J.; Dmytruk, K.V.; Sibirny, A.A. 100 Years Later, What Is New in Glycerol Bioproduction? Trends Biotechnol. 2020, 38, 907-916. [CrossRef]

68. Santos, H.; da Costa, M.S. Compatible solutes of organisms that live in hot saline environments. Environ. Microbiol. 2002, 4, 501-509. [CrossRef] [PubMed]

69. Alfredsson, G.A.; Kristjánsson, J.K.; Hjörleifsdottir, S.; Stetter, K.O. Rhodothermus marinus, gen. nov. sp. nov., a thermophilic halophilic bacterium from submarine hot springs in Iceland. J. Gen. Microbiol. 1988, 134, 299-306. [CrossRef]

70. Ventosa, A.; Nieto, J.J.; Oren, A. Biology of aerobic moderately halophilic bacteria. Microbiol. Mol. Biol. Rev. 1998, 62, 504-544. [CrossRef] [PubMed]

71. Andrei, A.; Banciu, H.L.; Oren, A. Living with salt: Metabolic diversity of archaea inhabiting saline ecosystems. FEMS Microbiol. Lett. 2012, 330, 1-9. [CrossRef] [PubMed]

72. Welsh, D.T. Ecological significance of compatible solute accumulation by micro-organisms: From single cells to global climate. FEMS Microbiol. Rev. 2000, 24, 263-290. [CrossRef] [PubMed] 
73. Benaroudj, N.; Hee Lee, H.; Goldberg, A.L. Trehalose accumulation during cellular stress protects cells and cellular proteins from damage by oxygen radicals. J. Biol. Chem. 2001, 276, 24261-24267. [CrossRef]

74. Santos, H.; da Costa, M.S. Organic solutes from thermophiles and hyperthermophiles. Meth. Enzymol. 2001, 334, $302-315$.

75. Martins, L.O.; Huber, R.; Huber, H.; Stetter, K.O.; da Costa, M.S.; Santos, H. Organic solutes in hyperthermophilic archaea. Appl. Environ. Microbiol. 1997, 63, 896-902. [CrossRef]

76. Lamosa, P.; Burke, A.; Peist, R.; Huber, R.; Liu, M.-Y.; Silva, G.; Rodrigues-Pousada, C.; LeGall, J.; Maycock, C.; Santos, H. Thermostabilization of proteins by diglycerol phosphate, a new compatible solute from the hyperthermophile Archaeoglobus fulgidus. Appl. Environ. Microbiol. 2000, 66, 1974-1979. [CrossRef]

77. da Costa, M.S.; Santos, H.; Galinski, E.A. An overview of the role and diversity of compatible solutes in Bacteria and Archaea. Adv. Biochem. Eng. Biotechnol. 1998, 61, 117-153.

78. Borges, N.; Ramos, A.; Raven, N.D.; Sharp, R.J.; Santos, H. Comparative study of the thermostabilizing properties of mannosylglycerate and other compatible solutes on model enzymes. Extremophiles 2002, 6, 209-216. [CrossRef]

79. McCollom, T.M.; Seewald, J.S. Abiotic synthesis of organic compounds in deep-sea hydrothermal environments. Chem. Rev. 2007, 107, 382-401. [CrossRef] [PubMed]

80. Bassez, M.-P. Is high-pressure water the cradle of life? J. Phys. Condens. Matter 2003, 15, L353. [CrossRef]

81. Lopez, A.; Fiore, M. Investigating prebiotic protocells for a comprehensive understanding of the origins of life: A prebiotic systems chemistry perspective. Life 2019, 9, 49. [CrossRef] [PubMed]

82. McCollom, T.M.; Ritter, G.; Simoneit, B.R.T. Lipid synthesis under hydrothermal conditions by Fischer-Tropsch-type reactions. Orig. Life Evol. Biosph. 1999, 29, 153-166. [CrossRef] [PubMed]

83. McCollom, T.M.; Simoneit, B.R.T. Abiotic formation of hydrocarbons and oxygenated compounds during thermal decomposition of iron oxalate. Orig. Life Evol. Biosph. 1999, 29, 167-186. [CrossRef] [PubMed]

84. Kelley, D.S.; Baross, J.A.; Delaney, J.R. Volcanoes, fluids, and life at mid-ocean ridge spreading centers. Annu. Rev. Earth Planet. Sci. 2002, 30, 385-491. [CrossRef]

85. Westall, F.; Hickman-Lewis, K.; Hinman, N.; Gautret, P.; Campbell, K.A.; Bréhéret, J.G.; Foucher, F.; Hubert, A.; Sorieul, S.; Dass, A.V.; et al. A hydrothermal-sedimentary context for the origin of life. Astrobiology 2018, 18, 259-293. [CrossRef]

86. Shigemasa, Y.; Matsuda, Y.; Sakazawa, C.; Matsuura, T. Formose reactions II. The photochemical formose reaction. Bull. Chem. Soc. Jpn. 1977, 50, 222-226. [CrossRef]

87. Agarwal, V.K.; Schutte, W.; Greenberg, J.M.; Ferris, J.P.; Briggs, R.; Connor, S.; Van de Bult, C.P.; Baas, F. Photochemical reactions in interstellar grains photolysis of $\mathrm{CO}, \mathrm{NH}_{3}$, and $\mathrm{H}_{2} \mathrm{O}$. Orig. Life Evol. Biosph. 1985, 16, 21-40. [CrossRef]

88. Briggs, R.; Ertem, G.; Ferris, J.P.; Greenberg, J.M.; McCain, P.J.; Mendoza-Gomez, C.X.; Schutte, W. Comet Halley as an aggregate of interstellar dust and further evidence for the photochemical formation of organics in the interstellar medium. Orig. Life Evol. Biosph. 1992, 22, 287-307. [CrossRef] [PubMed]

89. Bernstein, M.P.; Dworkin, J.P.; Sandford, S.A.; Cooper, G.W.; Allamandola, L.J. Racemic amino acids from the ultraviolet photolysis of interstellar ice analogues. Nature 2002, 416, 401-403. [CrossRef] [PubMed]

90. Nuevo, M.; Bredehöft, J.H.; Meierhenrich, U.J.; d'Hendecourt, L.; Thiemann, W.H. Urea, Glycolic acid, and glycerol in an oganic residue produced by ultraviolet irradiation of interstellar/pre-cometary ice analogs. Astrobiology 2010, 10, 245-256. [CrossRef] [PubMed]

91. Patel, B.H.; Percivalle, C.; Ritson, D.J.; Duffy, C.D.; Sutherland, J.D. Common origins of RNA, protein and lipid precursors in a cyanosulfidic protometabolism. Nat. Chem. 2015, 7, 301-307. [CrossRef]

92. Kaiser, R.I.; Maity, S.; Jones, B.M. Synthesis of prebiotic glycerol in interstellar ices. Angew. Chem. Int. Ed. 2015, 54, 195-200. [CrossRef]

93. Meinert, C.; Myrgorodska, I.; de Marcellus, P.; Buhse, T.; Nahon, L.; Hoffmann, S.V.; d'Hendecourt, L.S.; Meierhenrich, U.J. Ribose and related sugars from ultraviolet irradiation of interstellar ice analogs. Science 2016, 352, 208-212. [CrossRef]

94. Civiš, S.; Szabla, R.; Szyja, B.M.; Smykowski, D.; Ivanek, O.; Knížek, A.; Kubelík, P.; Šponer, J.; Ferus, M.; Šponer, J.E. TiÖ2catalyzed synthesis of sugars from formaldehyde in extraterrestrial impacts on the early Earth. Sci. Rep. 2016, 6, 23199. [CrossRef]

95. Fedoseev, G.; Chuang, K.-J.; Qasim, D.; Linnartz, H.; Ioppolo, S.; van Dishoeck, E.F.; Linnartz, H. Formation of glycerol through hydrogenation of CO ice under prestellar core conditions. Astrophys. J. 2017, 842, 1-9. [CrossRef]

96. Cronin, J.R.; Chang, S. Organic matter in meteorites: Molecular and isotopic analyses of the Murchison meteorite. In The Chemistry of Life's Origins; Greenberg, J.M., Ed.; Kluwer Academic Publishers: Dordrecht, The Netherlands, 1993; pp. $209-258$.

97. Cooper, G.; Kimmich, N.; Belisle, W.; Sarinana, J.; Brabham, K.; Garrel, L. Carbonaceous meteorites as a source of sugar-related organic compounds for the early Earth. Nature 2001, 414, 879-883. [CrossRef]

98. Pizzarello, S.; Cooper, G.W.; Flynn, G.J. The nature and distribution of the organic material in carbonaceous chondrites and interplanetary dust particles. In Meteorites and the Early Solar System II; Lauretta, D.S., McSween, H.Y., Eds.; University of Arizona Press: Tucson, AZ, USA, 2006; pp. 625-651.

99. Sephton, M.A. Organic compounds in carbonaceous meteorites. Nat. Prod. Rep. 2002, 19, 292-311. [CrossRef]

100. Eichberg, J.; Sherwood, E.; Epps, D.E.; Oró, J. Cyanamide mediated syntheses under plausible primitive earth conditions. IV. The synthesis of acylglycerols. J. Mol. Evol. 1977, 10, 221-230. [CrossRef] [PubMed]

101. Odom, D.G.; Lahav, N.; Chang, S. Prebiotic nucleotide oligomerization in a fluctuating environment: Effects of kaolinite and cyanamide. J. Mol. Evol. 1979, 12, 259-264. [CrossRef] [PubMed] 
102. Tsanakopoulou, M.; Sutherland, J.D. Cyanamide as a prebiotic phosphate activating agent-catalysis by simple 2-oxoacid salts. Chem. Comm. 2017, 53, 11893-11896. [CrossRef] [PubMed]

103. Kaur, S.; Ohri, A.; Sharma, P. Could Purines Be Formed from Cyanamide and Cyanoacetylene in a Prebiotic Earth Environment? ACS Omega 2019, 4, 12771-12781. [CrossRef] [PubMed]

104. Österberg, R.; Orgel, L.E.; Lohrmann, R. Further studies of urea-catalyzed phosphorylation reactions. J. Mol. Evol. 1973, 2, 231-234. [CrossRef] [PubMed]

105. Rushdi, A.I.; Simoneit, B.R.T. Abiotic condensation synthesis of glyceride lipids and wax esters under simulated hydrothermal conditions. Orig. Life Evol. Biosph. 2006, 36, 93-108. [CrossRef]

106. Rushdi, A.I.; Simoeit, B.R.T.; Deamer, D.W. Abiotic formation of acylglycerols under simulated hydrothermal conditions and self-assembly properties of such lipid products. Adv. Space Res. 2007, 40, 1649-1658.

107. Rushdi, A.I.; Simoneit, B.R.T. Lipid formation by aqueous Fischer-Tropsch-type synthesis over a temperature range of 100 to $400{ }^{\circ}$ C. Orig. Life Evol. Biosph. 2001, 31, 103-118. [CrossRef]

108. Fiore, M.; Strazewski, P. Prebiotic lipidic amphiphiles and condensing agents on the early Earth. Life 2016, 6, 17. [CrossRef]

109. Oro, J. Chemical synthesis of lipids and the origin of life. J. Biol. Phys. 1995, 20, 135-147. [CrossRef]

110. Maurer, S.E.; Deamer, D.W.; Boncella, J.M.; Monnard, P.A. Chemical evolution of amphiphiles: Glycerol monoacyl derivatives stabilize plausible prebiotic membranes. Astrobiology 2009, 9, 979-987. [CrossRef] [PubMed]

111. Epps, D.E.; Nooner, D.W.; Eichberg, J.; Sherwood, E.; Oró, J. Cyanamide mediated synthesis under plausible primitive earth conditions. VI. The synthesis of glycerol and glycerophosphates. J. Mol. Evol. 1979, 14, 235-241. [CrossRef] [PubMed]

112. Gull, M.; Ge, T.; Yingwu, W.; Chao, H.; Zhan, S.; Hongming, Y.; Shouhua, F. Resolving the enigma of prebiotic C-O-P bond formation: Prebiotic hydrothermal synthesis of important biological phosphate esters. Heteroat. Chem. 2010, 21, 161-167.

113. Gull, M.; Cafferty, B.J.; Hud, N.V.; Pasek, M.A. Silicate-promoted phosphorylation of glycerol in non-aqueous solvents: A prebiotically plausible route to organophosphates. Life 2017, 7, 29. [CrossRef]

114. Gull, M.; Zhou, M.; Fernández, F.M.; Pasek, M.A. Prebiotic phosphate ester syntheses in a deep eutectic solvent. J. Mol. Evol. 2014, 78, 109-117. [CrossRef]

115. Burcar, B.; Pasek, M.A.; Gull, M.; Cafferty, B.J.; Velasco, F.; Hud, N.V. Darwin's warm little pond: A one-pot reaction for prebiotic phosphorylation and the mobilization of phosphate from minerals in a urea-based solvent. Angew. Chem. Int. Ed. 2016, 55, 13249-13253. [CrossRef]

116. Gibard, C.; Bhowmik, S.; Karki, M.; Kim, E.K.; Krishnamurthy, R. Phosphorylation, oligomerization and self-assembly in water under potential prebiotic conditions. Nat. Chem. 2018, 10, 212-217. [CrossRef]

117. Gull, M.; Pasek, M.A. Is struvite a prebiotic mineral? Life 2013, 3, 321-330. [CrossRef]

118. Pasek, M.A.; Kee, T.P. On the origin of phosphorylated biomolecules. In Origins of Life: The Primal Self-Organization; Egel, R., Lankenau, D.-H., Mulkidjanian, A.Y., Eds.; Springer: Berlin/Heidelberg, Germany, 2011; pp. 57-84.

119. Schoffstall, A.M. Prebiotic phosphorylation of nucleosides in formamide. Orig. Life Evol. Biosph. 1976, 7, 399-412. [CrossRef]

120. Schoffstall, A.M.; Mahone, S.M. Formate ester formation in amide solutions. Orig. Life Evol. Biosph. 1988, 18, 389-396. [CrossRef]

121. Furukawa, Y.; Kim, H.J.; Hutter, D.; Benner, S.A. Abiotic regioselective phosphorylation of adenosine with borate in formamide. Astrobiology 2015, 15, 259-267. [CrossRef] [PubMed]

122. Saladino, R.; Crestini, C.; Ciciriello, F.; Pino, S.; Costanzo, G.; Di Mauro, E. From formamide to RNA: The roles of formamide and water in the evolution of chemical information. Res. Microbiol. 2009, 160, 441-448. [CrossRef] [PubMed]

123. Saladino, R.; Crestini, C.; Pino, S.; Costanzo, G.; Di Mauro, E. Formamide and the origin of life. Phys. Life Rev. 2012, 9, 84-104. [CrossRef] [PubMed]

124. Saladino, R.; Carota, E.; Botta, G.; Kapralov, M.; Timoshenko, G.N.; Rozanov, A.Y.; Krasavin, E.; Di Mauro, E. Meteorite-catalyzed syntheses of nucleosides and of other prebiotic compounds from formamide under proton irradiation. Proc. Natl. Acad. Sci. USA 2015, 112, 2746-2755. [CrossRef] [PubMed]

125. Pasek, M.A. Thermodynamics of Prebiotic Phosphorylation. Chem. Rev. 2019, 120, 4690-4706. [CrossRef] [PubMed]

126. Zhang, Q.; De Oliveira, V.K.; Royer, S.; Jérôme, F. Deep eutectic solvents: Syntheses, properties and applications. Chem. Soc. Rev. 2012, 41, 7108-7146. [CrossRef] [PubMed]

127. Abbott, A.P.; Capper, G.; Davies, D.L.; Rasheed, R.K.; Tambyrajah, V. Novel solvent properties of choline chloride/urea mixtures. Chem. Commun. 2003, 1, 70-71. [CrossRef]

128. Abbott, A.P.; Boothby, D.; Capper, G.; Davies, D.L.; Rasheed, R.K. Deep eutectic solvents formed between choline chloride and carboxylic acids: Versatile alternatives to ionic liquids. J. Am. Chem. Soc. 2004, 126, 9142-9147. [CrossRef]

129. Abbott, A.P.; Harris, R.C.; Ryder, K.S.; Agostino, C.D.; Gladden, L.F.; Mantle, M.D. Glycerol eutectics as sustainable solvent systems. Green Chem. 2011, 13, 82-90. [CrossRef]

130. Austin, S.M.; Waddell, T.G. Prebiotic synthesis of vitamin B6- type compounds. Orig. Life Evol. Biosph. 1999, 29, 287-296. [CrossRef]

131. Miller, S.L. A production of amino acids under possible primitive earth conditions. Science 1953, 117, 528-529. [CrossRef] [PubMed]

132. Miller, S.L.; Schlesinger, G. Prebiotic syntheses of vitamin coenzymes: I. cysteamine and 2-mercaptoethane-sulfonic acid (coenzyme M). J. Mol. Evol. 1993, 36, 302-307. [CrossRef] [PubMed]

133. Lago, J.L.; Burcar, B.T.; Hud, N.V.; Febrian, R.; Mehta, C.; Bracher, P.J.; Atlas, Z.D.; Pasek, M.A. The prebiotic provenance of semi-aqueous solvents. Orig. Life Evol. Biosph. 2020, 50, 1-14. [CrossRef] 
134. Schwartz, A.W. Phosphorus in prebiotic chemistry-an update and a note on plausibility. In Handbook of Astrobiology; Kolb, V., Ed.; CRC Press: Boca Raton, FL, USA, 2019; pp. 355-359.

135. Gull, M.; Omran, A.; Feng, T.; Pasek, M.A. Silicate-, magnesium ion-, and urea-induced prebiotic phosphorylation of uridine via pyrophosphate; revisiting the hot drying water pool scenario. Life 2020, 10, 122. [CrossRef] [PubMed]

136. Gull, M. Prebiotic Phosphorylation Reactions on the Early Earth. Challenges 2014, 5, 193-212. [CrossRef]

137. Pasek, M.A.; Gull, M.; Herschy, B. Phosphorylation on the early earth. Chem. Geol. 2017, 475, 149-170. [CrossRef]

138. Hazen, R.M. Evolution of minerals. Sci. Am. 2010, 302, 58-65. [CrossRef] [PubMed]

139. Pasek, M.A. Rethinking early Earth phosphorus geochemistry. Proc. Natl. Acad. Sci. USA 2008, 105, 853-858. [CrossRef]

140. Pasek, M.A.; Lauretta, D. Extraterrestrial flux of potentially prebiotic C, N, and P to the early Earth. Orig. Life Evol. Biosph. 2008, 38, 5-21. [CrossRef]

141. Bryant, D.E.; Greenfield, D.; Richard, D.; Benjamin, W.; Johnson, R.G.; Herschy, B.; Smith, C.; Pasek, M.A.; Telford, R.; Scowen, I.; et al. Hydrothermal modification of the Sikhote-Alin iron meteorite under low $\mathrm{pH}$ geothermal environments. A plausibly prebiotic route to activated phosphorus on the early Earth. Geochim. Cosmochim. Acta 2013, 109, 90-112. [CrossRef]

142. Pasek, M.A.; Lauretta, D.S. Aqueous corrosion of phosphide minerals from iron meteorites: A highly reactive source of prebiotic phosphorus on the surface of the early Earth. Astrobiology 2005, 5, 515-535. [CrossRef] [PubMed]

143. Pasek, M.A.; Harnmeijer, J.P.; Buick, R.; Gull, M.; Atlas, Z. Evidence for reactive reduced phosphorus species in the early Archean ocean. Proc. Natl. Acad. Sci. USA 2013, 110, 10089-10094. [CrossRef] [PubMed]

144. Weber, A.L. Model of early self-replication based on covalent complementarity for a copolymer of glycerate-3-phosphate and glycerol-3-phosphate. Orig. Life Evol. Biosph. 1989, 19, 79-186. [CrossRef] [PubMed]

145. Walde, P. Surfactant assemblies and their various possible roles for the origin(s) of life. Orig. Life Evol. Biosph. 2006, 36, 109-150. [CrossRef] [PubMed]

146. Hargreaves, W.R.; Mulvihill, S.J.; Deamer, D.W. Synthesis of phospholipids and membranes in prebiotic conditions. Nature 1977, 266, 78-80. [CrossRef]

147. Epps, D.E.; Sherwood, E.; Eichberg, J.; Oró, J. Cyanamide mediated syntheses under plausible primitive earth conditions V. The synthesis of phosphatidic acids. J. Mol. Evol. 1978, 11, 279-292. [CrossRef]

148. Rao, M.; Eichberg, J.; Oró, J. Synthesis of Phosphatidylcholine under possible primitive earth conditions. J. Mol. Evol. 1982, 18, 196-202. [CrossRef]

149. Rao, M.; Eichberg, J.; Oró, J. Synthesis of phosphatidylethanolamine under possible primitive earth conditions. J. Mol. Evol. 1987, 25, 1-6. [CrossRef]

150. Bonfio, C.; Caumes, C.; Duffy, C.D.; Patel, B.H.; Percivalle, C.; Tsanakopoulou, M.; Sutherland, J.D. Length-selective synthesis of acylglycerol-phosphates through energy-dissipative cycling. J. Am. Chem. Soc. 2019, 141, 3934-3939. [CrossRef]

151. Kim, H.-J.; Ricardo, A.; Illangkoon, H.; Kim, M.J.; Carrigan, M.A.; Frye, F.; Benner, S.A. Synthesis of Carbohydrates in MineralGuided Prebiotic Cycles. J. Am. Chem. Soc. 2011, 133, 9457-9468. [CrossRef]

152. Simonov, A.N.; Pestunova, O.P.; Matvienko, L.G.; Snytnikov, V.N.; Snytnikova, O.A.; Tsentalovich, Y.P.; Parmon, V.N. Possible prebiotic synthesis of monosaccharides from formaldehyde in presence of phosphates. Adv. Space. Res. 2007, 40, 1634-1640. [CrossRef]

153. Breslow, R.; Ramalingam, V.; Appayee, C. Catalysis of glyceraldehyde synthesis by primary or secondary amino acids under prebiotic conditions as a function of pH. Orig. Life Evol. Biosph. 2013, 43, 323-329. [CrossRef] [PubMed]

154. Breslow, R.; Cheng, Z.-L. L-amino acids catalyze the formation of an excess of D-glyceraldehyde, and thus of other D sugars, under credible prebiotic conditions. Proc. Natl. Acad. Sci. USA 2010, 107, 5723-5725. [CrossRef] [PubMed]

155. Steer, A.M.; Bia, N.; Smith, D.K.; Clarke, P.A. Prebiotic synthesis of 2-deoxy-D-ribose from interstellar building blocks promoted by amino esters or amino nitriles. Chem. Commun. 2017, 53, 10362-10365. [CrossRef] [PubMed]

156. Weber, A.L. Prebiotic sugar synthesis: Hexose and hydroxy acid synthesis from glyceraldehyde catalyzed by iron (III) hydroxide oxide. J. Mol. Evol. 1992, 35, 1-6. [CrossRef]

157. Kolb, V.; Orgel, L.E. Phosphorylation of glyceric acid in aqueous solution using trimetaphosphate. Orig. Life Evol. Biosph. 1996, 26, 7-13. [CrossRef]

158. Krishnamurthy, R.; Guntha, S.; Eschenmoser, A. Regioselective $\alpha$-phosphorylation of aldoses in aqueous solution. Angezw. Chem. Int. Ed. 2000, 39, 2281-2285. [CrossRef]

159. Coggins, A.; Powner, M. Prebiotic synthesis of phosphoenol pyruvate by $\alpha$-phosphorylation-controlled triose glycolysis. Nat. Chem. 2017, 9, 310-317. [CrossRef]

160. Imbault, A.L.; Gong, J.; Farnood, R. Photocatalytic production of dihydroxyacetone from glycerol on $\mathrm{TiO}_{2}$ in acetonitrile. RSC Adv. 2020, 10, 4956-4968. [CrossRef]

161. Weber, A.L. The triose model: Glyceraldehyde as a source of energy and monomers for prebiotic condensation reactions. Orig. Life Evol. Biosph. 1987, 17, 107-119. [CrossRef]

162. Weber, A.L.; Hsu, V. Energy-rich glyceric acid oxygen esters: Implications for the origin of glycolysis. Orig. Life Evol. Biosph. 1990, 20, 145-150. [CrossRef] [PubMed]

163. Pinto, J.P.; Gladstone, G.R.; Yung, Y. Photochemical production of formaldehyde in Earth's primitive atmosphere. Science 1980, 210, 183-185. [CrossRef] [PubMed]

164. Weber, A. Nonenzymatic formation of "energy-rich" lactoyl and glyceroyl thioesters from glyceraldehyde and a thiol. J. Mol. Evol. 1984, 20, 157-166. [CrossRef] [PubMed] 
165. Deamer, D.W. The first living systems: A bioenergetic perspective. Microbiol. Mol. Biol. Rev. 1997, 61, 239-261. [CrossRef] [PubMed]

166. Anastasi, C.; Crowe, M.A.; Sutherland, J.D. Two-step potentially prebiotic synthesis of $\alpha$-d-cytidine- $5^{\prime}$-phosphate from Dglyceraldehyde-3-phosphate. J. Am. Chem. Soc. 2007, 129, 24-25. [CrossRef] [PubMed]

167. Hein, J.E.; Tse, E.; Blackmond, D.G. A route to enantiopure RNA precursors from nearly racemic starting materials. Nat. Chem. 2011, 3, 704-706. [CrossRef]

168. Orgel, L.E. The implausibility of metabolic cycles on the prebiotic Earth. PLoS Biol. 2008, 6, 005-0012. [CrossRef]

169. Zhang, R.S.; McCullum, E.O.; Chaput, J.C. Synthesis of two mirror image 4-helix junctions derived from glycerol nucleic acid. J. Am. Chem. Soc. 2008, 130, 5846-5847. [CrossRef]

170. Liu, H.; Gao, J.; Lynch, S.R.; Saito, Y.D.; Maynard, L.; Kool, E.T. A four-base paired genetic helix with expanded size. Science 2003, 302, 868-871. [CrossRef]

171. Yang, Y.-W.; Zhang, S.; McCullum, E.O.; Chaput, J.C. Experimental Evidence That GNA and TNA were not sequential polymers in the prebiotic evolution of RNA. J. Mol. Evol. 2007, 65, 289-295. [CrossRef]

172. Karri, P.; Punna, V.; Kim, K.; Krishnamurthy, R. Base-pairing properties of a structural isomer of glycerol nucleic acid. Angezw. Chem. Int. Ed. 2013, 52, 5840-5844. [CrossRef] [PubMed]

173. Kim, K.; Punna, V.; Karri, P.; Krishnamurthy, R. Synthesis of phosphoramidites of isoGNA, an isomer of glycerol nucleic acid. Beilstein J. Org. Chem. 2014, 10, 2131-2138. [CrossRef] [PubMed]

174. Kobayashi, K.; Kasamatsu, T.; Kaneko, T.; Saito, T. Production of Organic Compounds in Interstellar Space. In Exobiology: Matter, Energy, and Information in the Origin and Evolution of Life in the Universe; Chela-Flores, J., Raulin, F., Eds.; Springer: Dordrecht, The Netherlands, 1998; pp. 213-216.

175. Ehrenfreund, P.; Spaans, M.; Holm, N.G. The evolution of organic matter in space. Philos. Trans. R. Soc. A 2011, 369, 538-554. [CrossRef] [PubMed]

176. Kwok, S. Complex organics in space from Solar System to distant galaxies. Astron. Astrophys. Rev. 2016, 24, 1-27. [CrossRef]

177. Nakano, H.; Hirakawa, N.; Matsubara, Y.; Yamashita, S.; Okuchi, T.; Asahina, K.; Tanaka, R.; Suzuki, N.; Naraoka, H.; Takano, Y.; et al. Precometary organic matter: A hidden reservoir of water inside the snow line. Sci. Rep. 2020, 10, 1-13. [CrossRef]

178. Ehrenfreund, P.; Cami, J. Cosmic carbon chemistry: From the interstellar medium to the early Earth. Cold Spring Harb. Perspect. Biol. 2010, 2, a002097. [CrossRef]

179. Mason, B. Organic matter from space. Sci. Am. 1963, 208, 43-49. [CrossRef]

180. Oró, J.; Mills, T. Chemical evolution of primitive solar system bodies. Adv. Space Res. 1989, 9, 105-120. [CrossRef]

181. Pohorille, A. From organic molecules in space to the origins of life and back. Adv. Space Res. 2002, 30, 1509-1520. [CrossRef]

182. Cockell, C.S. The origin and emergence of life under impact bombardment. Philos. Trans. R. Soc. Lond. B Biol. Sci. 2006, 361, 1845-1856. [CrossRef]

183. Osinski, G.R.; Cockell, C.S.; Pontefract, A.; Sapers, H.M. The Role of Meteorite Impacts in the Origin of Life. Astrobiology 2020, 20, 1121-1149. [CrossRef] [PubMed]

184. Fegley, B.; Prinn, R.G.; Hartman, H.; Watkins, G.H. Chemical effects of large impacts on the Earth's primitive atmosphere. Nature 1986, 319, 305-308. [CrossRef] [PubMed]

185. Chyba, C.; Sagan, C. Endogenous production, exogenous delivery and impact-shock synthesis of organic molecules: An inventory for the origins of life. Nature 1992, 355, 125-132. [CrossRef] [PubMed]

186. McKay, C.P.; Borucki, W.J. Organic synthesis in experimental impact shocks. Science 1997, 276, 390-392. [CrossRef] [PubMed]

187. Ferris, J.P. Catalysis and prebiotic RNA synthesis. Orig. Life Evol. Biosph. 1993, 23, 307-315. [CrossRef] [PubMed]

188. Ferris, J.P. Prebiotic synthesis on minerals: Bridging the prebiotic and RNA worlds. Biol. Bull. 1999, 196, 311-314. [CrossRef]

189. Mattia Bizzarri, B.; Botta, L.; Pérez-Valverde, M.I.; Saladino, R.; Di Mauro, E.; García-Ruiz, J.M. Silica Metal Oxide Vesicles Catalyze Comprehensive Prebiotic Chemistry. Chemistry 2018, 24, 8126-8132. [CrossRef]

190. Dalai, P.; Sahai, N. Mineral-lipid interactions in the origins of life. Trends Biochem. Sci. 2019, 44, 331-341. [CrossRef]

191. Jheeta, S.; Joshi, P.C. Prebiotic RNA synthesis by montmorillonite catalysis. Life 2014, 4, 318-330. [CrossRef]

192. Cleaves, H.J., II; Michalkova, S.A.; Hill, F.C.; Leszczynski, J.; Sahai, N.; Hazen, R. Mineral-organic interfacial processes: Potential roles in the origins of life. Chem. Soc. Rev. 2012, 41, 5502-5525. [CrossRef]

193. Schoonen, M.; Smirnov, A.; Cohn, C. A perspective on the role of minerals in prebiotic synthesis. AMBIO 2004, 33, 539-551. [CrossRef] [PubMed]

194. Meunier, A.; Petit, S.; Cockell, C.S.; Albani, A.E.; Beaufort, D. The Fe-rich clay microsystems in basalt-komatiite lavas: Importance of Fe-smectites for pre-biotic molecule catalysis during the Hadean eon. Orig. Life Evol. Biosph. 2010, 40, 253-272. [CrossRef] [PubMed]

195. Siegel, B.Z.; Siegel, S.M. Enzyme-mimicking properties of silicates and other minerals. Adv. Space Res. 1981, 1, 27-36. [CrossRef]

196. Paecht-Horowitz, M. Clays and other minerals in prebiotic processes. Orig. Life Evol. Biosph. 1984, 14, 307-314. [CrossRef]

197. Ertem, G. Montmorillonite, oligonucleotides, RNA and origin of life. Orig. Life Evol. Biosph. 2004, 34, 549-570. [CrossRef]

198. Cockell, C.S.; Lee, P.; Broady, P.; Lim, D.S.S.; Osinski, J.; Parnell, J.; Koeberl, C.; Pesonen, L.; Salminen, J. Effects of asteroid and comet impacts on habitats for lithophytic organisms-A synthesis. Meteorit. Planet. Sci. 2005, 40, 1901-1916. [CrossRef]

199. Cockell, C.S.; Lee, P. The biology of impact craters-A review. Biol. Rev. 2002, 77, 279-310. [CrossRef] 